\title{
Nanocellulose Production: Exploring the Enzymatic Route and Residues of Pulp and Paper Industry
}

\author{
Michele Michelin ${ }^{1}$, Daniel G. Gomes ${ }^{1, * \mathbb{D}}$, Aloia Romaní ${ }^{1}$, Maria de Lourdes T. M. Polizeli ${ }^{2}(\mathbb{D}$ \\ and José A. Teixeira ${ }^{1}$ (D) \\ 1 CEB-Centre of Biological Engineering, Universidade do Minho, Campus Gualtar, 4710-057 Braga, Portugal; \\ mimichelin@ceb.uminho.pt (M.M.); aloia@ceb.uminho.pt (A.R.); jateixeira@deb.uminho.pt (J.A.T.) \\ 2 Department of Biology, Faculdade de Filosofia Ciências e Letras de Ribeirão Preto, Universidade de São \\ Paulo, Ribeirão Preto SP 14040-901, Brazil; polizeli@ffclrp.usp.br \\ * Correspondence: danielg_gomes@ceb.uminho.pt; Tel.: +351-253-601968
}

Academic Editor: Derek J. McPhee

Received: 2 July 2020; Accepted: 23 July 2020; Published: 28 July 2020

\begin{abstract}
Increasing environmental and sustainability concerns, caused by current population growth, has promoted a raising utilization of renewable bio-resources for the production of materials and energy. Recently, nanocellulose (NC) has been receiving great attention due to its many attractive features such as non-toxic nature, biocompatibility, and biodegradability, associated with its mechanical properties and those related to its nanoscale, emerging as a promising material in many sectors, namely packaging, regenerative medicine, and electronics, among others. Nanofibers and nanocrystals, derived from cellulose sources, have been mainly produced by mechanical and chemical treatments; however, the use of cellulases to obtain NC attracted much attention due to their environmentally friendly character. This review presents an overview of general concepts in NC production. Especial emphasis is given to enzymatic hydrolysis processes using cellulases and the utilization of pulp and paper industry residues. Integrated process for the production of NC and other high-value products through enzymatic hydrolysis is also approached. Major challenges found in this context are discussed along with its properties, potential application, and future perspectives of the use of enzymatic hydrolysis as a pretreatment in the scale-up of NC production.
\end{abstract}

Keywords: nanocellulose; enzymatic hydrolysis; cellulases; eucalyptus Kraft pulp; biorefinery

\section{Introduction}

Nowadays, there is an increasing interest in the sustainable production of biofuels, chemicals, and materials from lignocellulosic biomasses due to growing environmental concerns related to the use of non-renewable fossil resources. In fact, reaching this target is one of the most challenging issues faced by our society, being a required step in the transition towards a cleaner development based on a circular economy. In this context, cellulosic ethanol production has been the most important driving force for the development of lignocellulosic biorefineries in the last decades. Nevertheless, lignocellulose-to-ethanol production is still not economically viable due to the high initial investment and elevated cost of production related to the deconstruction of the recalcitrant structure of lignocellulosic materials.

To tackle this limitation, the scientific community made huge efforts on the production of value-added products from other fractions (namely, hemicellulose and lignin) coupled with efficient ethanol production. In fact, several lignocellulosic biorefinery schemes have been proposed in the literature, in which cascading processes are suggested for the development of multiproduct facilities. Generally, these processes involve the fractionation of the lignocellulosic biomass, which usually requires chemical or physical pretreatments to recover the main macromolecules (cellulose, 
hemicellulose, and lignin) facilitating the access of enzymes (i.e., cellulases) to cellulose and the subsequent enzymatic hydrolysis prior sugar fermentation into biofuels or other value-added compounds (i.e., lactic acid, succinic acid, etc.). In this sense, most of the studies are focused on the disruption of the recalcitrant structure of cellulosic materials. Cellulases are able to hydrolyze the amorphous regions of cellulose about 30 times faster than crystalline regions [1]. For this reason, the solid fibrous residue resulting from cellulosic ethanol processes using an enzymatic hydrolysis route is composed mainly by crystalline cellulose [1,2].

In addition to the interest in cellulose as a putative source of fermentable sugars, cellulose is a well-known material used for a long time in the manufacturing of a wide range of products and materials [3]. Recently, the production of cellulose at a nanoscale (known as nanocellulose (NC)), used for the development of novel materials, has received much attention due to its interesting properties [4]. In fact, this issue has been already addressed in a large number of publications and patents [5-7]. Most of these studies have focused on NC production, its characterization, and the utilization of these nanostructures in nanocomposites, coatings, and films, or even in medical applications [8,9]. These nanostructures are classified in cellulose nanocrystals (CNCs) and nanofibers (CNFs) and can be typically obtained using strong acid and mechanical treatments, respectively. The production of NC using strong acid hydrolysis, though, is not compatible with a biorefinery scheme, since costly steps of neutralization are required previous to the fermentation process, and other thermochemical processes (such as pyrolysis, liquefaction, and gasification) are not possible due to the high degree of depolymerization of macromolecules into monomers [10]. Therefore, the enzymatic hydrolysis route to obtain NC is shown as a promising alternative to chemical catalysis, as it is compatible with biological processes and yields nanostructures easier to functionalize and with high thermal stability [11]. The use of enzymes in processes of NC production is less explored in the literature comparatively to chemical and mechanical processes. Nevertheless, several authors have evaluated this strategy in combination with other treatments and/or integrated with the production of biofuels [2,11,12].

Despite the numerous works reviewing NC production and their multiple applications [6,7], the enzymatic route is rarely approached. Ribeiro and co-workers [13] have recently reviewed the enzymatic pathway for NC production, focusing on the characterization methods and the catalytic mechanism. On the other hand, Pirich et al. [14] recently published a review dedicated to enzyme-based strategies to produce nanocellulose.

Taking all the above into account, this review aims to provide an overview of the sources of cellulose to produce NC, comparing the chemical/mechanical and enzymatic processes. In addition, the description of the main enzymes involved and their action mechanism, including the main advantages and drawbacks, are also described and discussed, as well as the main properties of the nanoscale cellulose. Moreover, the integrated production of NC and second-generation ethanol or other value-added compounds following the biorefinery concept is also approached. To conclude, the market, possible applications, and the main challenges related to enzymatic hydrolysis for NC production are also addressed.

\section{Cellulose Structure and Types}

Cellulose is the most abundant polymer worldwide with a production of $7.5 \times 10^{11}$ ton/year and is the main component of plants, placed in the cell wall. Chemically, cellulose is constituted by a linear homopolysaccharide of $\beta$-D-glucopyranose monomers linked by $\beta-1,4$ glycosidic bonds, achieving a degree of polymerization (DP) between 10,000-15,000, which is dependent on the plant species.

The three $\mathrm{OH}^{-}$groups present in the anhydroglucose unit form strong intra- and intermolecular hydrogen bonding networks with the following glucose unit in the same chain and with a different chain, respectively [15]. In the crystalline region, these $\mathrm{OH}^{-}$networks are strong and packed, which confers interesting features such as toughness, strength, fibrous, insoluble in water, and highly resistant to organic solvents. Therefore, its most important identified properties are: the structure forming microfibrils, the hierarchical organization (including crystalline and amorphous regions), and a glass 
transition temperature, higher than its temperature of degradation [16]. In nature, near to 36 molecules of cellulose are typically assembled together into elementary fibers (protofibrils), which are packed in microfibrils, being assembled into cellulose fibers [3]. Figure 1 shows the hierarchical structure of cellulose, which is composed of fibrils displaying a crystalline structure (highly ordered region) and an amorphous structure (disordered region) [15].

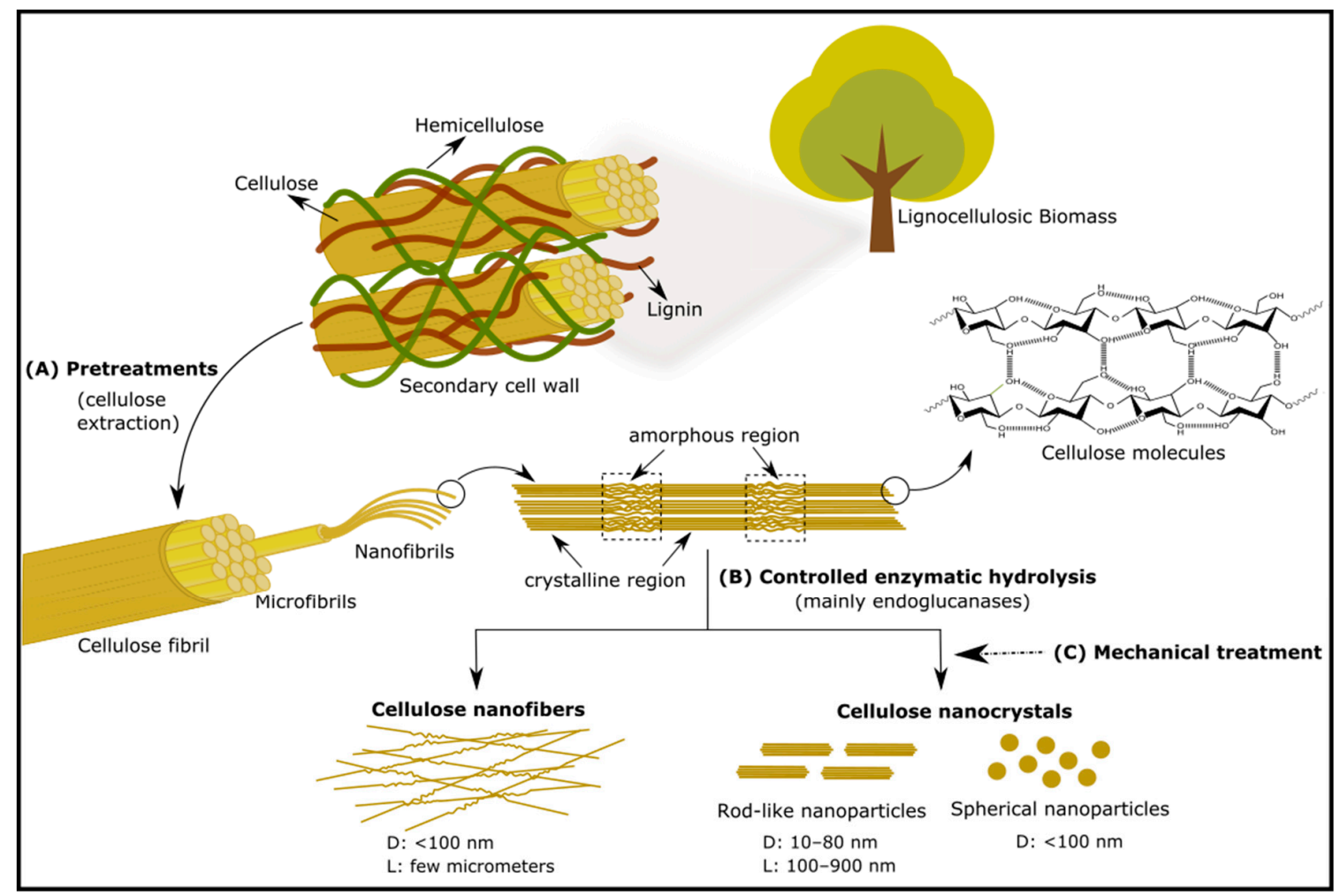

Figure 1. Process for nanocellulose (NC) production through enzymatic hydrolysis. (A) Pretreatments of the lignocellulosic biomass for cellulose extraction; (B) Controlled enzymatic hydrolysis for production of cellulose nanofibers and cellulose nanocrystals (rod-like and spherical) and their respective sizes; (C) Indication of the possible application of mechanical treatment after enzymatic hydrolysis, usually employed to obtain more uniform particles.

The native allomorph of cellulose is known as cellulose I, which can be transformed into other polymorphs or allomorphs, depending on the plant source and the chemical or thermal treatments used for their extraction. Therefore, identified polymorphs of cellulose are cellulose I, II, IIII $, \mathrm{III}_{\mathrm{II}}, \mathrm{IV}_{\mathrm{I}}$, and $\mathrm{IV}_{\mathrm{II}}$ [3]. Cellulose type I arises in two allomorphs, $\mathrm{I}_{\alpha}$ and $\mathrm{I}_{\beta}$. On the other hand, the cellulose type II is obtained after re-crystallization using aqueous $\mathrm{NaOH}$ [16], or it can also be produced by mercerization, which aims to swell native cellulose in concentrated $\mathrm{NaOH}$ solutions, removing the swelling agent after that [3]. Compared to cellulose I (that runs in parallel chains direction), cellulose II (that has antiparallel chains packing) shows a more stable structure. Cellulose $\mathrm{III}_{\mathrm{I}}$ and $\mathrm{III}_{\mathrm{II}}$ are obtained from ammonia (gas or liquefied) treatment of cellulose I and II, respectively. Cellulose $\mathrm{III}_{\mathrm{II}}$ is characterized by a disordered phase of cellulose. Otherwise, cellulose $\mathrm{IV}_{\mathrm{I}}$ and $\mathrm{IV}_{\mathrm{II}}$ are prepared using cellulose $\mathrm{III}_{\mathrm{I}}$ or $\mathrm{III}_{\mathrm{II}}$, respectively, by heating treatment up to $260{ }^{\circ} \mathrm{C}$ in glycerol. As cellulose III, cellulose IV can be reverted to structures I or II in high temperature and wet environment [3]. 


\section{Processing of Lignocellulosic Biomass for Cellulose Extraction}

\subsection{Main Source of Cellulose and Industrial Process of Extraction}

Different classifications exist concerning putative raw materials as sources of cellulose [17]. Among them, the most interesting classification from an environmentally-friendly point of view divides the sources of cellulose into [6]: (i) primary, in which the cellulose is the main product of the industrial activity, including fibers for textile or paper, wood for building or energy crops for biofuels production, such as cotton, flax fibers, hardwood, and softwood pulps; (ii) secondary, that includes non-processed byproducts from industrial processes of transformation (such as rice husks, corncob, wheat straw, wood bark, oilseed rape, etc.); and (iii) tertiary, which considers residues obtained from the use and/or transformation processes, such as pulp, newspapers, sugarcane bagasse, paper sludge or agri-food wastes (e.g., tea residue).

Traditionally, the pulp and paper industry is the most important supplier of cellulose for NC production, using delignified and bleached pulps [7]. Moreover, bleached pulp wastes from this industry are more easily transformed into $\mathrm{NC}$, reducing the cost of the process and the consumption of chemicals and energy [18]. Therefore, researchers started to work directly using purified cellulose for NC production, such as microcrystalline cellulose or bleached Kraft pulp [4]. The main species used for cellulose extraction include hardwoods (such as eucalyptus, birch, aspen, poplar), softwoods (pine, spruce, fir, larch, hemlock), as well as agro-industrial residues (sugarcane bagasse, wheat, and rice straws) $[6,19]$. The industrial manufacturing process for cellulose pulps involves the preparation of raw material, the pulping process and bleaching. During the pulping step, wood is reduced to wood chips, and lignin is solubilized to obtain cellulose fiber using several chemical methods: (i) Sulfite pulping consists of a process where the wood chips are treated with $\mathrm{H}_{2} \mathrm{SO}_{3}$ and $\mathrm{HSO}_{2}{ }^{-}$ions to disrupt lignin from cellulose fibers. (ii) For the Kraft process, the wood chips are submitted to $\mathrm{NaOH}$ and $\mathrm{NaS}_{2}$ treatments using high temperature and pressure to remove lignin from cellulose. (iii) In the soda process, which is the most employed process for agro-industrial residues, and $\mathrm{NaOH}$ at high temperatures is used to solubilize lignin from cellulose fibers [20]. In addition, chemical-mechanical pulping combines the chemical and mechanical refining treatments, such as wood cooking with $\mathrm{NaOH}$ to remove lignin from cellulose fibers, and then they are submitted to mechanical treatment. After that, the use of enzymes (namely, xylanases and laccases) has been increasingly employed as an environmentally friendly strategy to eliminate the remaining lignin in the pulp and to reduce the chemicals consumption in the process [21]. Finally, the bleaching process consists in the complete removal of lignin using chemical, gases, and steam, to provide the required color for paper manufacturing.

\subsection{Alternative Sources and Methods for Cellulose Extraction}

In addition to cellulose pulps from wood, industrial processed and non-processed sources of cellulose, including wastes generated in the pulp and paper industries (namely, bark, chips, sawdust and sludge), are shown as interesting and attractive raw materials for NC production [6,22]. In fact, the selection of renewable materials as an alternative to non-renewable resources is required to achieve sustainable processes according to European directives. The minimization of residues by using environmentally friendly processes to produce renewable materials such as NC is in line with Agenda 2030 to achieve sustainable development. Moreover, this approach can provide economic benefits, increasing the industrial value chain [23]. Therefore, the evaluation of byproducts and wastes as a source of cellulose is also considered by industries and the scientific community [24].

As mentioned above, the most important pretreatments required for purified cellulose extraction, independently of the lignocellulosic biomass source, are the delignification or pulping and the bleaching for cellulose purification. The delignification process (or pulping) aims to remove non-cellulosic fractions based on an alkaline treatment with $\mathrm{NaOH}$ or $\mathrm{KOH}$ and mineral acids, such as acid-chlorite treatment. Nevertheless, these processes are usually improved using other non-chemical treatments (such as ultrasounds or microwaves) [6], when mainly agro-industrial residues are used. For instance, 
Espinosa and co-workers [25] used soda pulping $\left(100{ }^{\circ} \mathrm{C}, 150 \mathrm{~min}\right.$, and $7 \%$ of soda) for cellulose extraction from wheat straw, which increased $\alpha$-cellulose up to $62 \%$, decreasing the content of hemicellulose, lignin, and extractives. For improving the nanofibrillation of a semi-chemical soda pulp, three pretreatments (namely, mechanical treatment using a screw extruder and a high-pressure homogenizer, and enzymatic hydrolysis treatment with endoglucanases) were evaluated showing a significant decrease on the degree of polymerization of cellulose.

As an alternative to the traditional delignification process mentioned above, the use of advanced cascading conversion technologies, which enables the application of a biorefinery approach, is also desirable [18]. For instance, apple tree pruning and pea stalks were used for cellulose CNCs production after being pretreated by autohydrolysis (for hemicellulose solubilization) and organosolv-acetosolv $\left(60 \%, 180{ }^{\circ} \mathrm{C}\right.$, for $\left.90 \mathrm{~min}\right)$, as an alternative to conventional $\mathrm{NaOH}$ pretreatment. This study showed a significant effect of pretreatment on CNCs properties, in which organosolv and autohydrolysis were more appropriated to obtain more homogeneous and smaller size particles than $\mathrm{NaOH}$ treatment [18]. Liquid hot water $\left(120^{\circ} \mathrm{C}\right.$ and $\left.1 \mathrm{~atm}\right)$ was also employed for the extraction of cellulose fibers from plum seed shells and compared to alkali treatment with $\mathrm{NaOH}$ [26]. On the other hand, hydrothermal pretreatment combined with an organosolv process was also evaluated for sugarcane bagasse delignification, and it was refined by Bauer disk, yielding a pulp with $92 \%$ of cellulose that was used to produce nanofibrillated cellulose films employing an enzymatic treatment followed by high-intensity sonication [27]. Other alternative solvents, such as [ $\mathrm{Bminm}] \mathrm{Cl}$ ionic liquid, assisted by microwave heating $\left(130^{\circ} \mathrm{C}, 500 \mathrm{~W}\right)$ were used for cellulose extraction from sugarcane bagasse [28]. In addition, attention is also on the use of more environmentally-friendly solvents, such as the study described by Kwok and collaborators [29], who developed a methodology for the screening of less hazardous solvents for extracting high-value lignin before Kraft pulping to obtain cellulose. As described for the pulp and paper industry, the bleaching aims to completely remove lignin using chlorine in an acid media and to reduce the diameter of cellulose fibers, improving their features (including surface area, crystallinity, and aspect ratio). As for the pulping step, alternative processes for pulp bleaching have also been proposed (using hydrogen peroxide or ozone) to avoid the use of chlorine in this process. Recent technological developments in ozone-based pulp bleaching have been reviewed by Tripathi and collaborators [30]. Taking into account the different alternatives for cellulose extraction, the properties of cellulose nanostructures do not depend only on factors such as plant species, growing conditions, and part of the plant, but also the pretreatment used for the lignocellulosic biomass processing has demonstrated to have a significant influence on the mechanical and thermal performances, the crystallinity, morphology, and surface charge [6].

Regarding cellulose sources derived from the pulp and paper industry, most of the works collected in the literature refer to the use of Kraft pulps. Nevertheless, other processed residues from this industry, such as waste paper, which is composed mainly of cellulose (60-70\%), has also been used for NC production [22]. This residue is considered a promising source of cellulose since a previous treatment for cellulose extraction is not required. In fact, wastepaper is shown as a raw material with high potential since harsh conditions to produce NC are not necessary, which can yield up to $64 \%$ depending on the wastepaper used. Moreover, recycled paper mill sludge was also already evaluated for NC production [31]. Other byproducts from the pulp and paper industry, such as wood bark that still contains $45 \%$ of cellulose [32,33], could also be an interesting raw material to be evaluated.

\section{Nanocellulose Classification}

Nanostructures of cellulose are comprised by cellulose nanocrystals (CNCs) and cellulose nanofibrils (CNFs) (Figure 2), which are generally obtained by acid hydrolysis treatment and mechanical processing, respectively. In addition to these designations, other synonyms can be founded in literature. For CNCs, it is also used for nanocrystalline cellulose (NCC), crystallites, (nano)whiskers, and rod-like cellulose microcrystals. On the other hand, for CNFs, it can also be designated for microfibrillated cellulose (MFC), nanofibrillated cellulose (NFC), and cellulose microfibrils (CF) [4,34]. 

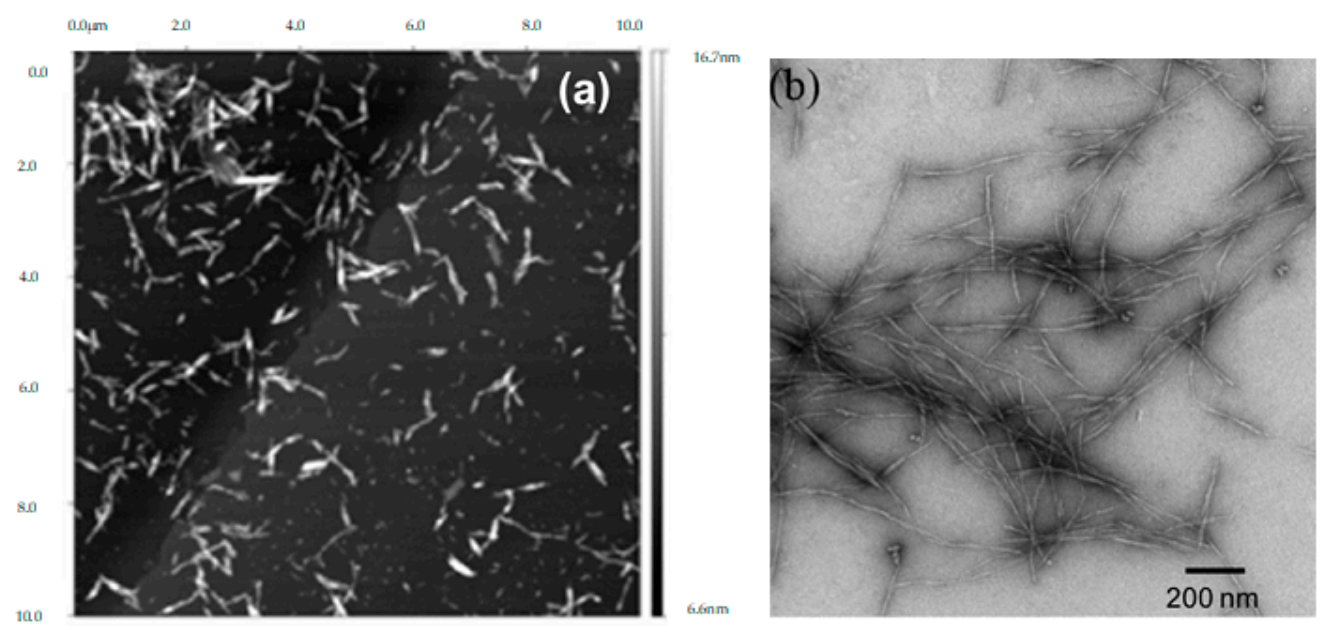

Figure 2. Images of cellulose nanocrystals (CNCs) by AFM (atomic force microscopy) (a) and cellulose nanofibrils (CNFs) by TEM (transmission electron microscopy) (b) obtained by enzymatic hydrolysis followed by mechanical treatment. Reprinted from [35] and [36], respectively, Copyright (2020), with permission from Elsevier.

Typically, the method for CNCs production involves controlled acidic digestion with $\mathrm{H}_{2} \mathrm{SO}_{4}$ of the amorphous regions of cellulose, first reported in 1951 by Ränby [3]. During acid hydrolysis, the amorphous regions are preferentially hydrolyzed, while crystalline regions present a higher resistance to acids attack [9]. After acid treatment, CNCs are washed with water to stop the reaction and are recovered by centrifugation. Then, dialysis is employed to remove free acid molecules, and a mechanical process (namely, sonication) is used to disperse the nanocrystals and obtain a stable suspension. Finally, concentration and drying of the suspension can also be carried out [9]. CNCs can be obtained from several cellulose sources and employing distinct methods; however, the use of wood or cotton (as the main source of cellulose) and acid hydrolysis with $\mathrm{H}_{2} \mathrm{SO}_{4}$ are still the most common routes for CNCs production [24]. Nevertheless, the use of strong concentrated acids is corrosive and incompatible with an environmentally-friendly process [9].

Regarding the production of CNFs, the delignified and bleached pulps are submitted to mechanical treatments, which includes equipment such as high-pressure homogenizers or microfluidizers, ball millings, steam explosion reactors, high-speed blenders, extruders, and ultrasonic equipment [7]. The main disadvantage here is the high energy consumption. Therefore, several works showed a reduction of energy requirements when mechanical processes are combined with enzymatic and/or chemical treatments (such as TEMPO (2,2,6,6-tetramethylpiperidine-1-oxyl) oxidation and carboxymethylation) [7,37-40].

Table 1 presents the NC production yield as well as the amount of chemicals and enzymes estimated from different production reports on literature, for a $100 \mathrm{~kg}$ base of raw material.

Table 1. Nanocellulose production, method of production, and yield obtained per $100 \mathrm{~kg}$ of raw material.

\begin{tabular}{|c|c|c|c|c|c|}
\hline Source of Cellulose & Production Method & Chemical/Enzymatic Load * & NC Type & Yield (kg) & Reference \\
\hline \multirow{3}{*}{$\begin{array}{l}\text { Sugarcane bagasse (SB) } \\
\text { Sugarcane straw (SS) }\end{array}$} & Alkali treatment & 2000 kg NaOH; & \multirow{3}{*}{$\mathrm{CNC}$} & \multirow{3}{*}{$\begin{array}{l}11.3(\mathrm{SB}) \\
12(\mathrm{SS})\end{array}$} & \multirow{3}{*}{ [11] } \\
\hline & Bleaching & $\begin{array}{l}680 \mathrm{~kg} \mathrm{NaOH} ; 190 \mathrm{~kg} \text { Acetic } \\
\text { acid; } 42 \mathrm{~kg} \mathrm{NaClO}{ }_{2}\end{array}$ & & & \\
\hline & Enzymatic treatment & 3.2-4.6 kg protein (Cellic CTec3) & & & \\
\hline \multirow[b]{2}{*}{ Wheat straw } & Soda pulping & $7 \mathrm{~kg} \mathrm{NaOH}$ & \multirow[b]{2}{*}{$\mathrm{CNF}$} & \multirow[b]{2}{*}{42.3} & \multirow[b]{2}{*}{ [25] } \\
\hline & Enzymatic treatment & $\begin{array}{c}\text { 18,600 ECU FiberCare }{ }^{\circledR} \\
\text { endoglucanase }\end{array}$ & & & \\
\hline \multirow{2}{*}{ Banana peels } & Delignification treatment & $100 \mathrm{~kg} \mathrm{KOH} ; 20 \mathrm{~kg} \mathrm{NaClO}{ }_{2}$ & \multirow{2}{*}{$\mathrm{CNF}$} & \multirow{2}{*}{$27-71 * *$} & \multirow{2}{*}{ [12] } \\
\hline & Acid treatment & $2-200 \mathrm{~kg} \mathrm{H}_{2} \mathrm{SO}_{4}$ & & & \\
\hline
\end{tabular}


Table 1. Cont.

\begin{tabular}{|c|c|c|c|c|c|}
\hline Source of Cellulose & Production Method & Chemical/Enzymatic Load * & NC Type & Yield (kg) & Reference \\
\hline \multirow{3}{*}{ Wood flour } & Alkali treatment & $\begin{array}{c}100 \text { kg calcium hypochlorite; } \\
10 \text { kg acetic acid }\end{array}$ & \multirow{3}{*}{$\begin{array}{c}\text { nano } \\
\text { structures }\end{array}$} & \multirow{3}{*}{11.43} & \multirow{3}{*}{ [41] } \\
\hline & Alkali bleaching & $40 \mathrm{~kg} \mathrm{NaOH} ; 240 \mathrm{~kg} \mathrm{H} \mathrm{O}_{2}$ & & & \\
\hline & Enzymatic treatment & $\begin{array}{c}5.4 \text { kg Cellic CTec2; } 0.6 \text { kg Cellic } \\
\text { HTec2 }\end{array}$ & & & \\
\hline \multirow{3}{*}{ Grapevine stems } & Alkaline treatment & 45 kg NaOH/100 kg r.m. & \multirow{3}{*}{$\mathrm{CNF}$} & \multirow{3}{*}{$15-20$} & \multirow{3}{*}{ [6] } \\
\hline & Bleaching & $\begin{array}{l}18 \mathrm{~kg} \mathrm{NaClO} \\
2 / 100 \mathrm{~kg} \\
\text { alkali-treated r.m. }\end{array}$ & & & \\
\hline & TEMPO Oxidation & $\begin{array}{l}1.6 \mathrm{~kg} \text { TEMPO radical; } 26 \mathrm{~kg} \\
\mathrm{NaBr} ; 900 \mathrm{~kg} \mathrm{NaClO} / 100 \mathrm{~kg} \\
\text { of cellulose }\end{array}$ & & & \\
\hline \multirow{3}{*}{ Grapevine pomace } & Alkaline treatment & 45 kg NaOH/100 kg r.m. & \multirow{3}{*}{$\mathrm{CNC}$} & \multirow{3}{*}{ 10-15 } & \multirow{3}{*}{ [6] } \\
\hline & Bleaching & $\begin{array}{l}18 \mathrm{~kg} \mathrm{NaClO}_{2} / 100 \mathrm{~kg} \\
\text { alkali-treated r.m. }\end{array}$ & & & \\
\hline & Acid Hydrolysis & $500 \mathrm{~kg} \mathrm{H}_{2} \mathrm{SO}_{4} / 100 \mathrm{~kg}$ cellulose & & & \\
\hline Cotton linters & Enzymatic treatment & $\begin{array}{l}\text { 200-2000 U of cellulose C on } \\
\text { an Ahiba Easydye }\end{array}$ & $\mathrm{CNC}$ & 80 & [42] \\
\hline
\end{tabular}

* calculated from published data; ${ }^{* *}$ per $100 \mathrm{~kg}$ of cellulose; ECU: endocellulase units; r.m: raw material.

\section{Nanocellulose Production by Enzymatic Hydrolysis}

The utilization of enzymes in the production of NC is rather complex and may refer to very distinct roles in the overall process, ranging from removing pectins and hemicellulose to the most common application of cellulases to produce NC. The focus of this review, however, will be the action of enzymes on the production step.

Despite the still common idea that CNCs are generally produced from acid hydrolysis while CNFs are produced from mechanical fibrillation (assisted by other processes), numerous studies have been conducted showing that the mechanisms for producing both materials are in fact more diverse; multiple works refer to the application of cellulases for the production of CNCs combined with acid hydrolysis or even with no chemicals being used (Table 2).

\subsection{Different Approaches for the Integration of Enzymatic Hydrolysis on Nanocellulose Production}

Table 2 lists some previous studies addressing the extraction of NC through an enzymatic process. Distinct process configurations have been used depending on different factors, such as the source of cellulose or the type of material being produced. In general terms, this process involves two main phases: the extraction of cellulose (see Section 3) and the production of NC. Studies reporting the utilization of raw materials, which still did not undergo any kind of processing, normally involve an initial mechanical (e.g., grinding, milling) and/or physicochemical (e.g., autohydrolysis, alkali, bleaching) pretreatment to extract cellulose (eliminating hemicellulose, lignin, and other components). Opposed to that, highly processed materials, such as bleached Kraft pulps [43-45], cotton linters [42,46] or microcrystalline cellulose [47], have no need for this step; typically, in these cases, only a minor preparation step is conducted, such as dispersing or swelling of the cellulosic material [48]. This is followed by the process of enzymatic modification of the cellulose-enriched solid, which will introduce different types of modification according to the enzymes being used.

In the particular case of CNFs production, the enzymatic hydrolysis is commonly followed by a mechanical step of fibrillation, such as homogenization [38,44], microfluidization [49,50], extrusion [25,51], and sonication [27,52], among others. Few studies have also reported no mechanical treatment step after hydrolysis [12,53-55], hence totally relying on the enzymes to produce the nanofibers. 
Table 2. General description of previous studies reporting the production of CNFs and CNCs by enzymatic hydrolysis.

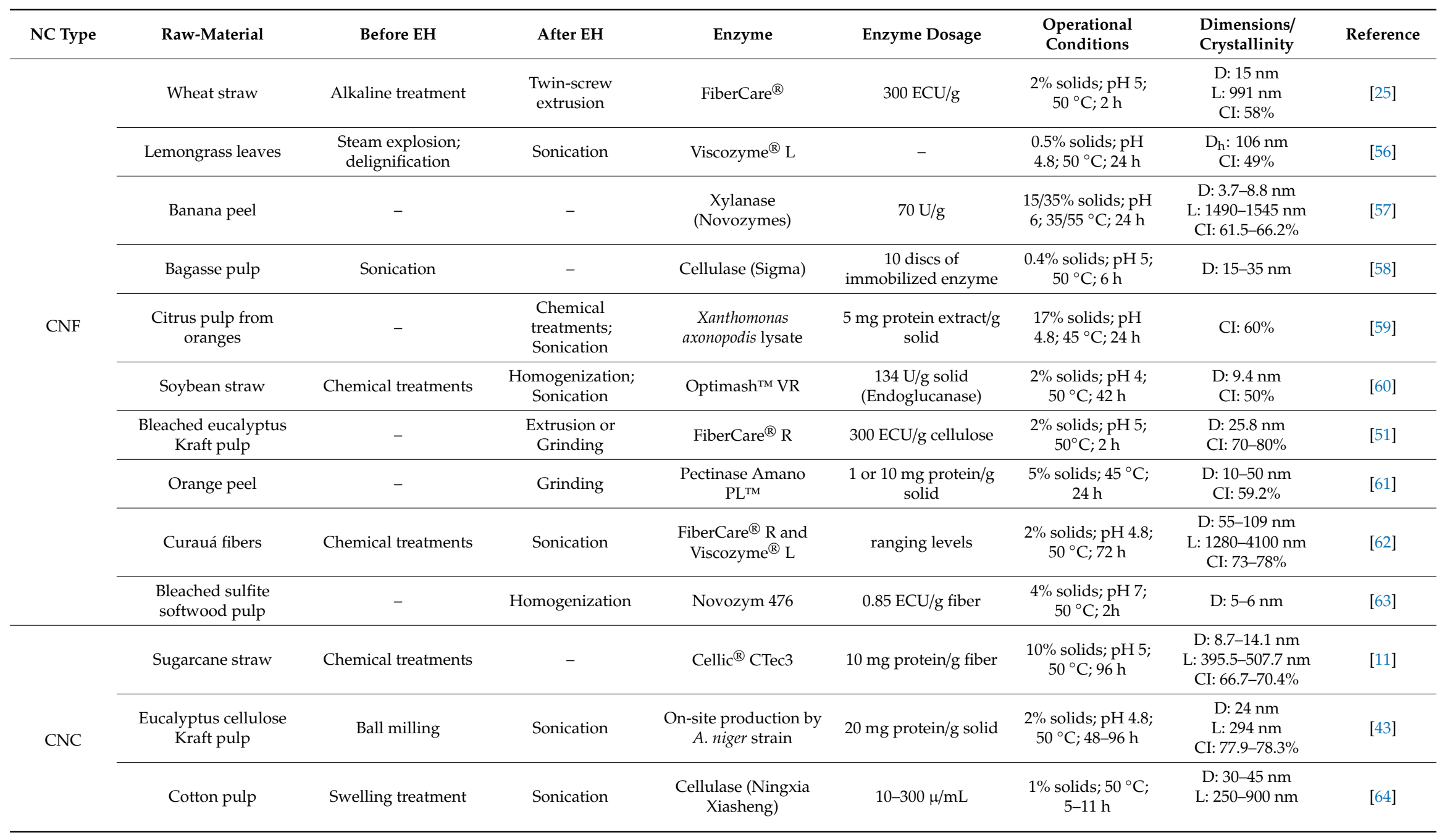


Table 2. Cont

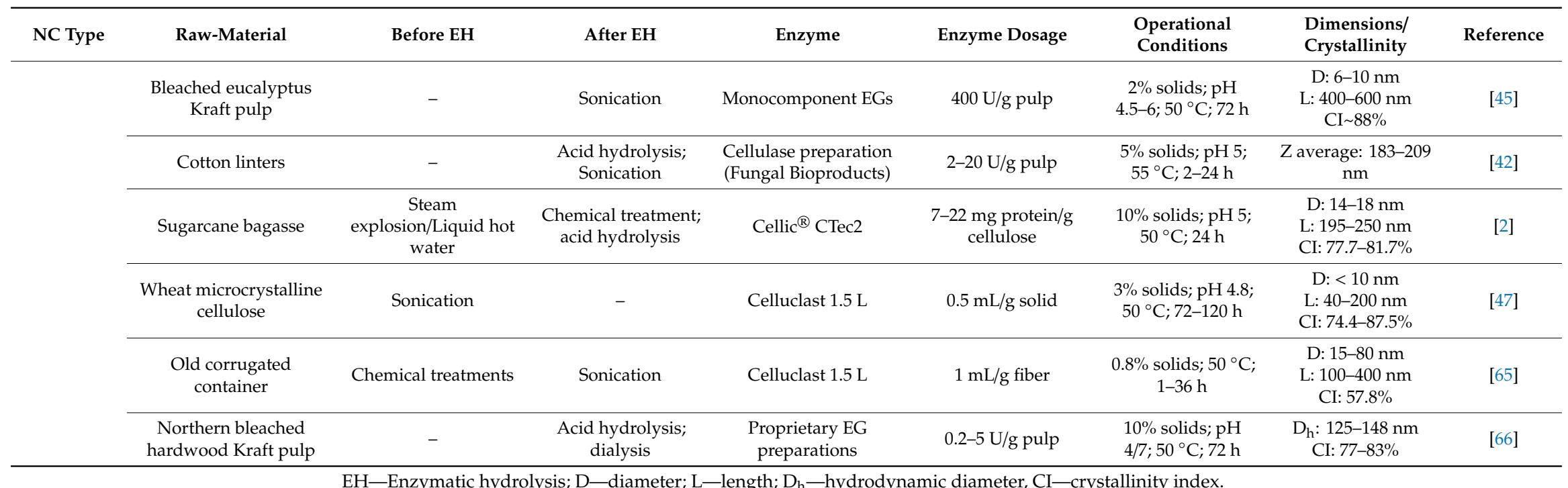

EH—Enzymatic hydrolysis; D—diameter; L—length; $\mathrm{D}_{\mathrm{h}}$-hydrodynamic diameter, CI—crystallinity index. 
Regarding the extraction of CNCs, the most common procedure consists on a sonication step after hydrolysis, allowing an intense fragmentation of NC into particles within a nanoscale size range [62] and their efficient dispersion, even though some authors have also described its use before hydrolysis [67]. Some studies have equally reported the application of sulfuric acid [42,68] or other chemicals [2] after enzymatic hydrolysis or, in total opposite, no treatment after enzymatic hydrolysis [11,48,69-71].

Either for CNFs or CNCs, it should be noted that there is no established procedure for their production, being instead of a case-specific approach that will largely depend on the initial raw material and the required properties for the final material.

\subsection{Mechanisms of Cellulolytic Enzymes}

Even though different classes of enzymes have been used for the extraction of NC, cellulases correspond to a large majority of these cases. Figure 3 presents an overall scheme of the enzymes involved in NC production. Their ability to attack cellulose fibers with a high selectivity enables different types of modifications over cellulose. Cellulases are a specific class of enzymes that directly catalyze the hydrolysis of cellulose into simpler sugars, hence being commonly produced by cellulolytic organisms such as those from the genera Clostridium, Trichoderma, and Aspergillus, among others [14].

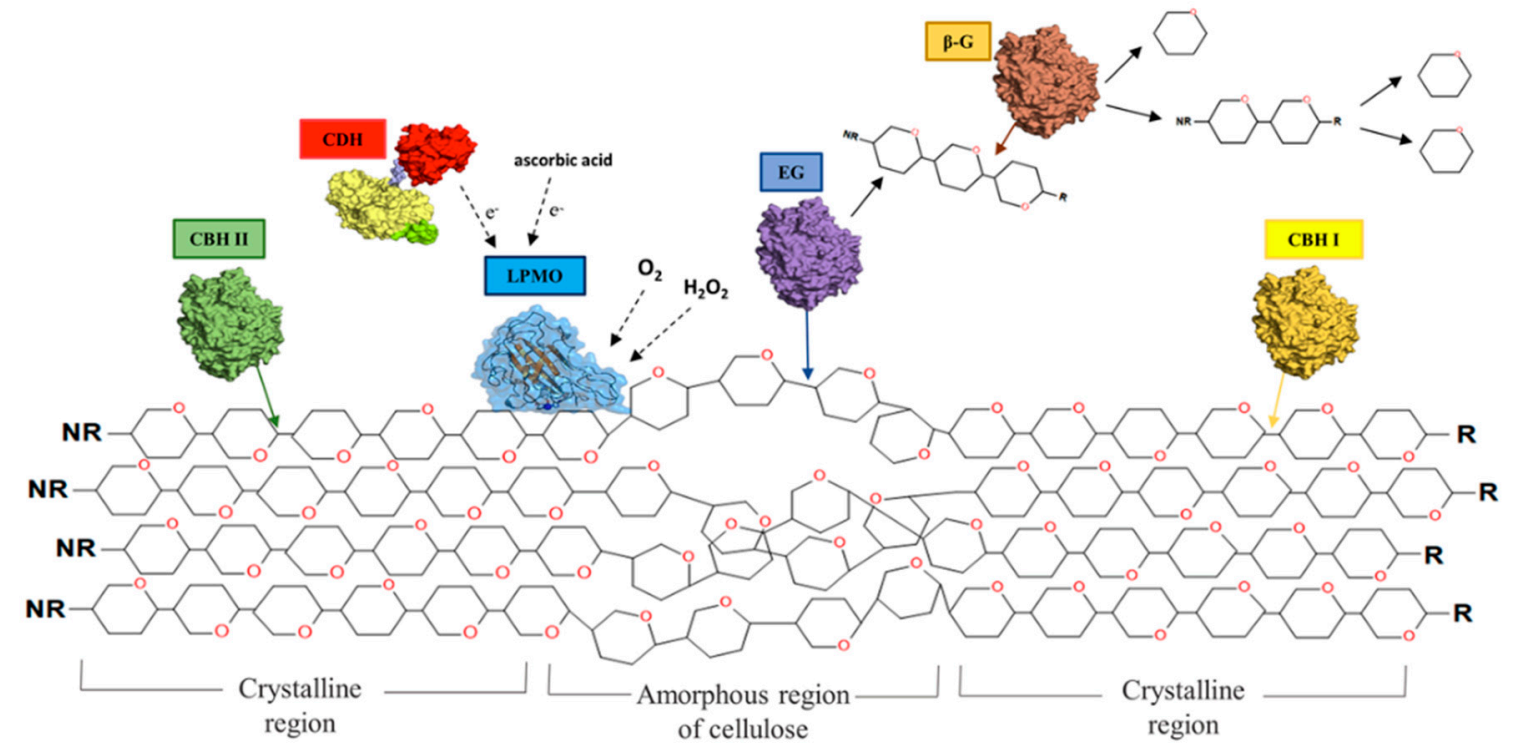

Figure 3. Overall schematic representation of the mechanisms involved in NC production by distinct classes of enzymes (adapted from [72]). R: reducing cellulose end; NR: nonreducing cellulose end; EG: endoglucanase; $\mathrm{CBH}$ I: exoglucanase removing cellobiose from $\mathrm{R}$ end; $\mathrm{CBH}$ II: exoglucanase removing cellobiose from NR end; $\beta$-G: $\beta$-glucosidase; $\mathrm{CDH}$ : cellobiose dehydrogenase; LPMO: lytic polysaccharide monooxygenases.

\subsubsection{The Cellulolytic Complex-Synergetic Deconstruction of Cellulose}

Cellulolytic organisms typically code for and secrete a large number of distinct cellulases, which, according to their specific mechanism, can be assigned into two main categories. Endoglucanases (EGs) cleave random internal $\beta-1,4$-glycosidic bonds of the cellulose chains, typically on the amorphous regions, originating new cellulose chain ends; cellobiohydrolases (CBHs), or exoglucanases, processively act on the different extremities of cellulose chains forming cellobiose units. One final class of cellulases refers to $\beta$-glucosidases, which hydrolyze cellobiose into glucose [73].

\subsubsection{The Major Role of EGs: Single Component vs. Enzymes Mixture}

Comparatively to the application of cellulases for the hydrolysis of lignocellulosic biomass, the production of NC represents a distinct paradigm. Either for CNCs or CNFs, cellulases would 
only require acting to a given extent and over specific sites of cellulose, providing the desired level of modification over cellulose structure. Opposed to this, cellulases cocktails for biomass hydrolysis aim for maximum conversion of complex sugars into fermentable ones [43]. Specifically, for producing $\mathrm{CNCs}$, the internal cellulose amorphous regions are the main target; these are hydrolyzed by EGs, resulting in smaller chains of crystalline cellulose. Something similar occurs for CNFs, although total removal of amorphous regions is not intended here, but instead, a reduction of cellulose chain length and the cleavage of inter-fiber linkages, which critically enhance posterior mechanical fibrillation. While in both cases EGs provide a desirable action towards a reduction in fiber length (DP) or an increase of crystallinity, the action of $\mathrm{CBHs}$ may result in undesirable fiber digestion into cellobiose. This fact highlights the important role of the composition of the enzymatic mixture on the final yield of extraction, raising the question of whether a complex cellulases cocktail may be the most suitable option in this context. In fact, even though several studies report the use of complex cocktails, such as Cellic CTec $[2,41,55]$, the most frequent option refers to the application of monocomponent endoglucanase, such as the Novozym $476[40,49,50]$, preparations for fibers modification, such as Fibercare R $[36,62,74]$ and Cellusoft L [75,76], or other individual EGs [45].

While an extended action of CBHs will result in a decrease of cellulose fibers [14], their action can be partially constrained by an accumulation of cellobiose through a mechanism of end-product inhibition [14], which would be favorable to prevent thorough enzymatic degradation. This would especially happen when low levels of $\beta$-glucosidase are present, which possibly explains numerous works employing Celluclast for NC production $[27,36,47,65]$.

\subsection{Other Enzymes in Nanocellulose Production}

Adding to the typically used cellulases, the process of NC production can be complemented with the application of other enzymes, either to provide a more purified cellulose material or to assist cellulases action.

\subsubsection{Xylanases}

After cellulases, xylanases is the most common class of enzymes applied for NC production. Acting on xylan residues, these enzymes can reduce the barrier formed by this polymer to cellulases action, significantly improving the extraction process [52]. When Song et al. [77] supplemented Cellic CTec2 with HTec2 in the hydrolysis of northern bleached hardwood Kraft (NBSK), glucose production increased approximately $40 \%$, even though only trace amounts of xylose were produced. According to Hu et al. [78], xylanases may also act synergistically with cellulases improving fibers' swelling and porosity, therefore increasing cellulases' accessibility to cellulose. On the other hand, partial/total elimination of xylan residues can also affect the final properties of NC. According to Siqueira et al. [45], the presence of xylan in the final nanomaterial can increase its colloidal stability since it affects fibers' aggregation. This may be attributed to the fact that xylan can act as an obstacle hindering the irreversible binding of hydroxyl groups on different cellulose fibers [79]. On a previous study of Winter et al. [80], the authors inclusively observed that the addition of xyloglucan to the produced CNCs improved its colloidal stability.

Xylanases can be used following different approaches, according to the initial raw material and the final expected product. Since enzymes are normally used to complement other chemical or mechanical treatments, the exclusive utilization of xylanases would be ultimately sufficient to produce some NC materials, as the removal of xylan already facilitates mechanical fibrillation. Tibolla et al. $[12,57,81]$ reported the utilization of xylanase (from Novozymes) to produce CNFs from banana peel solid, while Hassan et al. [82] described the production of MFC from date palm fruit stalks using commercial xylanase from Thermomyces lanuginosus. This, however, cannot be totally accomplished as cellulases and xylanases are usually found in each other's cocktails, even in trace amounts; ranging levels of xylanase activity have been reported in Cellic CTec2 [83], Celluclast [78], and Viscozyme [84], while Cellic HTec2 has also been reported to present some FPase 
and CMCase activities [83]. Consequently, on a low-hemicellulose solid scenario, the trace amounts of xylanase activity in the cellulase cocktail would possibly be enough for substantial hemicellulose hydrolysis $[41,55,85]$. Opposed to that, combined action of a cellulase and hemicellulase mixture may be advised when hemicellulose is present in higher amounts. Establishing the adequate levels of xylanase activity will be case-specific, as it would be based on the solid composition (including the presence of lignin) but also the desired properties for the final material. As an example, Chen et al. [86] observed that using a complex mixture of cellulases and xylanases allowed performing faster and with higher efficiency compared to exclusively cellulases, however, excessive use of xylanase did not lead to an increase of the extraction yield. On the other hand, in a recent study by Tong et al., [48], the authors observed that the ratio of cellulases-xylanases had a clear effect on final NC morphology. For a cellulase concentration superior to xylanase the final CNCs presented a spherical form with an average diameter ranging from $40-70 \mathrm{~nm}$. When xylanase concentration increased above the concentration of cellulase the CNCs clearly changed into a rod-like morphology, with their length increasing with the increase of xylanase $(750-1000 \mathrm{~nm})$.

\subsubsection{LPMOs}

Another class of enzymes that may assist NC production are the lytic polysaccharide monooxygenases (LPMOs), which have been increasingly used on cellulase cocktails employed for lignocellulosic hydrolysis. LPMOs act on cellulose chains by oxidative cleavage of glycosidic linkages, leading to the formation of oxidized glucose units in different positions, and consequently, a substrate more susceptible to hydrolysis by cellulases [87]. As for cellulases, LPMOs are typically secreted by saprotrophic fungi when grown on cellulose or a lignocellulosic material $[88,89]$. In the specific context of NC production, few studies have reported on the utilization of LPMOs. One example refers to the work conducted by $\mathrm{Hu}$ et al. [52] who studied the potential of combining individual endoglucanases with other enzymes, such LPMOs, to improve the fibrillation of a bleached Kraft pulp and/or the properties of the final material. Even though major differences were not found over the dimensions and morphology of the final fibers, some intrinsic properties were improved. LPMO family AA9 was found to increase the negative charge of cellulose fibers, possibly due to deposition of carboxylic acid or ketone structures resulting from the oxidative cleavage. According to the authors, this increase may have contributed to a significant rise of $\zeta$ (zeta) potential, aiding cellulose nanofibrillation and leading to a more stabilized suspension. In addition, in a recent study from Valls et al. [90], the authors observed that the addition of a bacterial LPMO to the cellulases mixture had numerous effects over NC production from cotton linters. LPMOs addition led to a significant increase in the amount of sugars released during extraction $(\sim 2$-fold $)$, the highest yield of extraction after mechanical fibrillation $(23 \%)$ and the lowest value of fibers length.

\subsection{Relevant Factors on the Enzymatic Process}

Similar to any enzyme-mediated process, NC production can be affected by several parameters; some of them directly influence cellulases efficiency (e.g., $\mathrm{pH}$, temperature, binding affinity), while others can dictate the way enzymes will act over cellulose, hence affecting the yield of the process and the properties of the final NC.

\subsubsection{Raw-Material Composition and Pretreatment}

The influence of the raw material on NC production occurs over different levels. A first issue to consider is the purity of the solid before enzymatic hydrolysis, which will rely on its initial composition and the application of efficient methods to remove non-cellulosic components (e.g., hemicellulose, lignin, extractives, protein). Since enzymatic hydrolysis almost exclusively changes cellulose (some enzyme preparations also have trace levels of xylanase activity), using a less purified solid will lead to final NC particles with more impurities. In this context, the presence of substantial amounts of lignin can represent a special challenge since cellulases have a reportedly high affinity to 
this component through irreversible binding [91]; the non-productive binding of cellulases is a major issue of lignocellulosic hydrolysis, leading to higher consumption of enzymes and a consequent increase in the process cost [92]. The real extent of it will depend on the amounts of lignin, but also its chemical structure, as lignin-cellulase interactions are mainly hydrophobic [93]. Adding to this, lignin may equally form a physical barrier to holocellulose in the substrate, critically affecting enzymes accessibility [94].

A most relevant aspect to discuss is also the distinct natural affinity of enzymes for different solids [95] or, on the other hand, the fact that distinct enzyme preparations may present diverse solid-enzyme interaction behaviors for the same solid [96]. It is widely known that enzyme-substrate interaction is a very complex mechanism that can be significantly affected not only by environmental factors (e.g., pH and surfactants), but also numerous structural properties of both enzymes and solids [97]. To a great extent, this may result from the specific affinity of carbohydrate-binding modules (CBMs), normally found in fungal cellulases, to different types of solids. In a previous work by McLean et al. [98], the authors observed that a CBM presented different affinities to the solid according to its crystallinity. Another point to consider is the possible influence of structural properties of the solid in the way enzymes will act over cellulose. As pointed out by Brinchi et al. [9], solids with high crystallinity, such as tunicate or bacterial cellulose, have an inferior fraction of amorphous regions that will be cleaved, which may result in the formation of larger CNCs.

\subsubsection{Enzyme Dosage and Hydrolysis Time}

Adding to the composition of the enzyme's mixture, the time of hydrolysis and the enzyme dosage are possibly the most important factors for the controlled and selective production of NC. On the basis of the well-established mechanisms of EGs and CBHs, it would be expected that employing different concentrations of the enzyme would, for the same period of time, result in different NC products.

In an early report from Chen et al. [67], the authors observed that while the levels of reducing sugars increased for growing enzyme dosages (10-19 FPU(filter paper units)/g), the yield of CNCs reached a maximum at $13 \mathrm{FPU} / \mathrm{g}$, decreasing for higher levels of the enzyme. The same behavior was observed in what concerns the time of hydrolysis, where a period of two days was found as the optimum time of hydrolysis. In a more recent study from Tong et al. [48], both the enzyme concentration and the hydrolysis time showed to clearly influence the morphology of CNCs. The utilization of lower levels of an enzyme (1-20 U/mL) resulted in rod-like CNCs with a length/diameter in the range of 600-800 nm and 20-40 nm, respectively. When enzyme concentration further increased to $50 \mathrm{U} / \mathrm{mL}$, a new spherical form of CNCs appeared, with an average diameter of $50 \mathrm{~nm}$, although coexisting with the rod-like morphology; a significant increase in enzyme concentration over levels of $300 \mathrm{U} / \mathrm{mL}$, together with a reduction on the hydrolysis time to $5 \mathrm{~h}$, led to CNCs being produced mostly in the spherical form. Similarly, under a low enzyme dosage $(10 \mathrm{U} / \mathrm{mL})$ the CNCs presented a rod-like morphology with a length decreasing from 800-900 nm for a 6 h hydrolysis, to 500-600 nm for $18 \mathrm{~h}$ hydrolysis. Similar observations were made by Chen et al. [64], who analyzed the CNCs produced under a range of operational times and enzyme dosages. For $5 \mathrm{~h}$ hydrolysis, the utilization of an enzyme dosage in the range of $10-50 \mu / \mathrm{mL}$ resulted exclusively in ribbon-like CNCs, with their dimensions decreasing with the amount of enzyme; an increase of the enzyme levels to $100-300 \mu / \mathrm{mL}$ led to the emergence of a granular form, becoming the exclusive morphology for the highest enzyme concentration. According to the authors, this seems to suggest that, contrary to the well-established idea that EGs only attacks internal amorphous regions of cellulose chains, under high-concentrations of enzymes they may also attack the crystalline regions, a process that can be especially favored with a previous swelling of the fiber. Furthermore, using an enzyme dosage as low as $20 \mu / \mathrm{mL}$, the length of the ribbon-like CNCs gradually decreased from 400-500 nm using hydrolysis of $5 \mathrm{~h}$, to 250-400 nm for hydrolysis of $11 \mathrm{~h}$, which highlights the possibility for rigorous control of CNCs morphology with these parameters. 


\subsubsection{Temperature and $\mathrm{pH}$}

Like all enzymes, cellulases optimally operate in a given range of $\mathrm{pH}$ and temperature values. Furthermore, these are associated with intrinsic properties of each enzyme, which may result in irreversible enzyme loss when operating in extreme conditions. Typically, cellulolytic enzymes present an optimum performance for a temperature ranging from $40-50{ }^{\circ} \mathrm{C}$ and a $\mathrm{pH}$ between 4 and 5 [99], which correspond to relatively mild operation conditions comparatively to the alternative chemical treatments.

A controlled $\mathrm{pH}$ during enzymatic extraction is particularly important since it will affect the adsorption/desorption of enzymes over cellulose [97], and consequently, their hydrolysis efficiency. A previous study from Rodrigues et al. [100] showed that when the $\mathrm{pH}$ increased from 4.8 to 9-10, significant conformational changes occurred in the structure of Cel7A; these, however, were reverted when $\mathrm{pH}$ was restored to 4.8. This fact may suggest that the exposure of cellulases to unusual values of $\mathrm{pH}$ has clear effects, but these can be reverted in some cases, which would mean no loss of enzyme. In the specific context of NC production, the common $\mathrm{pH}$ range is 4-5.8, with only a few exceptions; both Li et al. [46] and Paakko et al. [63] already reported the utilization of a pH of 7. This range of $\mathrm{pH}$ values is especially relevant for the cases when enzymatic treatment is preceded by an alkaline [11,101] or acidic [65,102] treatment, intended for hemicellulose/lignin removal, or the first step of NC production; this would require intensive washing and/or pH adjustment (e.g., dialysis) prior to the addition of enzymes.

As for $\mathrm{pH}$, the temperature range on enzymatic NC production is also very narrow, usually between 45 and $55^{\circ} \mathrm{C}$; some exceptions refer to non-fungal enzymes or the direct use of a microbial consortium. In a previous work by Teixeira et al. [103], CNCs were enzymatically produced using a blend of an EG and a $\beta$-glucosidase from Pyrococcus horikoshii and Pyrococcus furiosus, respectively, both hyperthermophilic; consequently, the hydrolysis temperature was $85^{\circ} \mathrm{C}$. In addition, Ma et al. [70] reported the utilization of the commercial preparation Giant A at $60{ }^{\circ} \mathrm{C}$, in accordance to its optimal temperature. Referring to the utilization of a microbial consortium (enriched in cellulase producers), Satyamurthy and Vigneshwaran [104] employed a hydrolysis temperature as low as $35^{\circ} \mathrm{C}$. In a total distinct situation from what occurs for $\mathrm{pH}$, temperature control will be even more critical. While operating under the optimum temperature range will lead to reduced hydrolysis, a substantial increase over this range can result in irreversible denaturation [105]. Considering how the temperature can significantly affect cellulases' efficiency, it is surprising the lack of studies clarifying its potential effect over processes of NC production.

\subsubsection{Composition of the Cellulases Mixture}

As for the selection of the enzyme dosage and operational time, the composition of the enzyme mixture will be equally critical for a controlled NC production. Different cellulases preparations can present different classes of enzymes (CBHs, EGs, hemicellulases, LPMOs), in different ratios and from different sources (e.g., fungal, bacterial). Accordingly, and also on the basis of their distinct selectivities, the overall synergism which one may achieve is rather complex and will result in very distinct products of hydrolysis.

A recent study by Siqueira et al. [45] showed that monocomponent EGs from different origins could present very distinct action mechanisms in the hydrolysis of bleached eucalyptus Kraft pulp (BEKP). The fungal EG from GH (glycoside hydrolase) family 7 was able to solubilize $9 \%$ of cellulose while the other fungal EG from GH family 45 hydrolyzed 5\%; the bacterial EG from GH family 5 only hydrolyzed $2 \%$. Another relevant fact was that, especially for the case of fungal enzymes, a considerable fraction of the solubilized sugars was glucose (75\% in the case of GH family 7), suggesting the capacity for this EG to either act on chain ends or to hydrolyze cellobiose. While this may represent a broader enzymatic activity range, it suggests a lower specificity for the amorphous regions of cellulose, a highly desirable trait in CNCs production; this capacity, however, was almost inexistent in the bacterial EG. In the scope of the possible effects that hemicellulose can have on cellulose hydrolysis, the conversion 
of xylan was also inspected. The fungal EG from GH family 7 was able to hydrolyze almost $25 \%$ of the xylan (mostly into xylo-oligomers), while for the EG from GH family 45 it was below 5\% and almost inexistent for the bacterial EG.

Another important work on the diversity of cellulase systems refers to the study conducted by Yarbrough et al. [10] comparing the efficiency of cellulose hydrolysis and NC production of Trichoderma reesei and Caldicellulosiruptor bescii enzyme systems. The former solubilized nearly $40 \%$ of cellulose, reaching a maximum NC yield around 30\% after $24 \mathrm{~h}$; C. bescii achieved cellulose hydrolysis above $80 \%$ with a peak NC yield of $42 \%$. Even more interesting than the levels of NC yield was the morphology of the extraction products. Through dynamic light scattering (DLS) they observed that $T$. reesei consistently produced an NC mixture composed mostly by CNFs, but also some CNCs. On the other hand, $C$. bescii showed a gradual transition over time, from an initial bimodal distribution (consisting of CNFs and CNCs) to a single and more uniform population of particle sizes, which was an intermediate of the initial ones and corresponded to CNCs. As pointed out by the authors, this may result from very distinct mechanisms of hydrolysis found in the most prevalent enzymes of these organisms. The largely abundant CBH Cel7A of $T$. reesei processively acts on crystalline cellulose, originating shorter cellulose fibrils. Opposed to that, the largely abundant multifunctional CelA complex of $C$. bescii (containing a catalytic domain of an EG family 9 and a CBH family 48) is able to bind cellulose in multiple locations and perform localized hydrolysis [106], previously referred to as "pit digging" action, which may allow fragmenting the CNFs into CNCs.

A recent review by Pirich et al. [14] refers to another potential key element in the properties of the selected enzymes. According to the authors, the absence of CBMs, which is commonly associated to a higher affinity of enzymes to crystalline cellulose, can possibly result in inferior hydrolysis of the crystalline regions, a desirable trait in nanocellulose production.

\subsubsection{Assistance by Mechanical Treatment}

Even though enzymatic processes were only more recently raised as a new option to complement the well-established extraction by mechanical fibrillation (CNFs) or acid hydrolysis (CNCs), numerous studies already showed that it could be used alone to produce NC materials (see Section 5.1). Despite this, adding to the initial pretreatments to obtain cellulose from raw materials (e.g., delignification), several other treatments can be employed to improve NC production or to control/optimize the properties of the final material (e.g., morphology, DP, crystallinity).

An early work from Zhu et al. [1] mentioned that the CNF sheets enzymatically produced from eucalyptus Kraft pulp had a reduction in their opacity from $93 \%$ to $24 \%$, only after 10 passes on a microfluidizer processor ( $200 \mu \mathrm{m}$ chamber). With a similar material, Qing et al. [36] observed that while the hydrolysis and refining led to a decrease in fibers' DP from 1000 to 287, a posterior microfluidization step (15 passes; $87 \mu \mathrm{m}$ chamber) still allowed a further decrease in the DP to 263; interestingly, the crystallinity increased during hydrolysis and refining from $55 \%$ to $60 \%$, but decreased afterwards to $57 \%$ after microfluidization, suggesting a superior homogenization effect over the crystalline regions. Another work from Lourenço et al. [44] reported that increasing the number of passes through a high-pressure homogenizer from 2 to 6 resulted in a decrease of DP from 1834 to 1504, while the extraction yield slightly increased from 22 to 26 .

Several studies also exist regarding the effects of sonication. One example consists of the work conducted by Campos et al. [62] on the production of CNFs from curaua and sugarcane bagasse. The authors observed that the diameter of fibers produced from curauá significantly decreased, from $78 \mu \mathrm{m}$ in the raw material, to approximately $4 \mu \mathrm{m}$ after enzymatic hydrolysis; although the bleaching before hydrolysis caused most of this reduction (to a diameter of $4.6 \mu \mathrm{m}$ ). Nonetheless, fibers with nanoscale dimensions were only obtained after the application of a sonication treatment $(20 \mathrm{~min})$, which reduced the diameter to 55-100 nm (depending on the enzyme mixture). This similarly occurred for fibers from sugarcane bagasse; their diameter after enzymatic hydrolysis ranged from 20-30 $\mu \mathrm{m}$ but significantly decreased to nearly $30 \mathrm{~nm}$ after sonication. Cui et al. [47] investigated the possible effects 
of applying multiple sonication steps (every $12 \mathrm{~h}$ ) with different time durations during the enzymatic production of CNCs from microcrystalline cellulose. For a $120 \mathrm{~h}$ hydrolysis, the yield of CNCs production was $17.6 \%$ without sonication, increasing to $19.3 \%$ and $22.6 \%$ for a sonication step of 30 and $60 \mathrm{~min}$, respectively. On the other hand, the length of the CNCs notoriously decreased from $200-400 \mathrm{~nm}$, without sonication, to $100-300 \mathrm{~nm}$ and $50-80 \mathrm{~nm}$ for sonication steps of 30 and $60 \mathrm{~min}$, respectively. Visible effects were also observed on the crystallinity index (CI) of the final particles: the application of a $30 \mathrm{~min}$ treatment led to a CI of $87.5 \%$, opposed to $83.4 \%$ with no treatment. Interestingly, the extension of sonication to periods of $60 \mathrm{~min}$ led to a decrease of the CI to $82.3 \%$, suggesting that after a specific point of fibers modification, both amorphous and crystalline regions are removed by sonication.

\subsection{Integration of Nanocellulose Production with Other Biotechnological Products}

While NC production can already be considered a high-value industry, providing diverse materials for electronics, medicine, energy storage, etc., it has been growingly associated with other compounds through an integrated production, as a mean to increase the viability of the process. A considerable fraction of NC worldwide production is, in fact, currently attributed to the pulp and paper industry [22], which saw NC as a particularly interesting co-product to improve its economic efficiency. Nevertheless, this integration can also be very relevant to the emergent concept of biorefineries, pursuing an integral valorization of the whole cellulosic material. In this sense, NC would be produced as the main product, resulting in a secondary stream of fermentable sugars which could be promptly converted into different compounds. In a different approach, the spent solid from the enzymatic hydrolysis of lignocellulosic materials, usually enriched in crystalline domains, could be used to produce CNCs. Despite this potential, literature reports on efficient integration of NC production with other value-added compounds are still scarce. This can be explained by direct competition between these classes of compounds: high production of one generally means low production of the other. In a recent study by Aguiar et al. [11] on the production of CNCs from hydrolysis of pretreated sugarcane and straw, the authors reported the production of a glucose stream with 84 and $75 \mathrm{~g} / \mathrm{L}$, respectively; the yield of CNCs production was $11.3 \%$ and $12 \%$, respectively, markedly inferior to the levels usually obtained by acid hydrolysis, as pointed out by the authors. Bondancia et al. [55] reported the production of a glucose stream with $91 \mathrm{~g} / \mathrm{L}$ and the presence of CNF structures in the final spent solid with a CI of $83 \%$, opposed to $72 \%$ before hydrolysis. Furthermore, Camargo et al. [2] described the production of CNCs from the spent solid of the hydrolysis of sugarcane bagasse to produce fermentable sugars (complemented with acid hydrolysis). Cypriano et al. [59] reported the potential of using the citrus pulp of floaters (residue from orange juice production) to produce hesperidin, NC, and ethanol; however, NC yield was $1.4 \%$ while the maximum ethanol titers were around $2 \mathrm{~g} / \mathrm{L}$. In addition, Tsukamoto et al. [107] referred to the utilization of orange waste to produce D-limonene, NC ( $3 \%$ yields), and ethanol (max. $8.5 \mathrm{~g} / \mathrm{L}$ ). In the true sense of a biorefinery, the recent work of Guirimand et al. [108] should be highlighted since it refers to the production of NC and xylitol, which do not directly compete on their precursors. Using wood Kraft pulp (78\% cellulose, 17\% hemicellulose), the authors employed a consolidated bioprocessing (CBP) system, consisting of a Saccharomyces cerevisiae strain with cell surface display of xylan-degrading enzymes (endoxylanase and $\beta$-glucosidase), to convert hemicellulose into xylitol while enriching the cellulose content of the solid to $87 \%$. This strategy resulted in the production of $3.7 \mathrm{~g} / \mathrm{L}$ of xylitol and simultaneously enabled the nanofibrillation of the final solid residue.

While the integration of different biotechnological products may always seem interesting, it is clear that when originating from the same solid fraction, the initially expected benefits could not be that high. The optimum scenario would achieve a maximum cellulose conversion either as NC or as glucose; obtaining cellobiose or other higher molecular weight cello-oligomers is not desirable and should be avoided. In this perspective, a careful selection of the enzyme mixture employed for NC extraction/solid conversion gains especial relevance. The specific ratio of different cellulase components, with characteristically different specificities and product ranges, will dictate the maximum cellulose conversion into products of interest. In a recent study from Siqueira et al. [45] the authors analyzed 
three different monocomponent endoglucanases (GH family 5, 7, and 45) for NC extraction from BEKP. The authors observed notorious differences, not only in their capacity to hydrolyze cellulose (the fungal GH 7 and 45 were clearly superior to the bacterial GH 5), but also in the distribution of the final products from hydrolysis; fungal GH family 7 obtained $75 \%$ of final sugars in the form of glucose, while for the bacterial GH family 5 these were almost totally in the form of cellobiose, an unfavorable scenario to produce other products by fermentation.

\subsection{Main Advantages of Enzymatic Nanocellulose Production}

Numerous advantages can be found from the application of enzymatic processes for NC production, either comparing to other chemical treatments (e.g., sulfuric acid, TEMPO) or even to exclusively mechanical extraction.

\subsubsection{Operation under Milder and Less Hazardous Conditions}

The first consequence from using enzymes is a partial or even total elimination of chemicals during extraction [12]; the extension of it will depend if the process is exclusively enzymatic or even aided by chemicals' action. Accordingly, the environmental impact of the overall process will be critically reduced since the amount of effluents with a chemical load will be inferior [109]. Another immediate result from this transition is operating under milder conditions, which includes moderate temperatures, pressures, and $\mathrm{pH}[15,55]$. From an operational standpoint, this can have numerous benefits, namely a safer operation, reduced costs of electricity and heat transfer utilities, and the utilization of cheaper construction materials (no requirement for anti-corrosion materials) $[110,111]$. In the particular context of a possible integration with a pre-established production process (e.g., cellulosic ethanol, pulp, and paper) this could also mean a smaller cost to adapt the industrial facility as less additional equipment and piping materials would be required.

An adequate approach to access these improvements would be to perform a life cycle assessment (LCA) analysis for both routes (enzymatic and non-enzymatic); but the application of this tool has still been poorly made in this context with only a few studies reported. Piccinno et al. [112] conducted an LCA analysis for the production of MFC from carrot waste by applying an enzymatic process and compared it with the results previously described by Figueirêdo et al. [113] for the production of MFC from cotton and unripe coconuts using sulfuric acid. According to the authors, the global warming potential of the sulfuric acid processes for coconut and cotton was 17.8 and 2.0 times superior, respectively, compared to the enzymatic extraction; this was mostly attributed to higher electricity consumption, which was also superior in a similar order of magnitude. Compared to the results from Li et al. [114], the global warming potential was very similar for a strategy of TEMPO-oxidation combined with homogenization but clearly superior to the other strategies (either using chloroacetic acid etherification and/or sonication). A detailed review of previous LCA analysis was performed by Kargarzadeh et al. [115].

It is also important to note that eliminating or reducing the amount of chemicals will facilitate the utilization of a final stream of sugars for the production of other products, such as biofuels, aiding in the implementation of a biorefinery concept; differently, the utilization of other production routes may require expensive neutralization steps [10].

In the line of reduced utilization of chemicals, some benefits may also be found over the final nanomaterials. One of these could be an inferior potential toxicity towards the human body, facilitating their application throughout nanomedicine, cosmetics, food, and pharmaceutics [13]. It is worth noting that possible benefits of this aspect are essentially related to the final purification and preparation of the NC-based product, which will require a more/less complex process according to its manufacturing process. From the perspective of the purified material, either CNFs or CNCs, no significant differences in their cytotoxicity have been reported according to the production route. According to Xu et al. [116], different properties of a nanoparticle can dictate its cytotoxicity, such as its dimension, shape, reactivity, 
and other chemical or physical properties. Rather than the NC production method, these are more likely to affect the final cytotoxicity of the NC particles.

\subsubsection{High Selectivity and Improved Nanocellulose Properties}

As a direct consequence of using enzymes, which can characteristically target more or less specific substrates or functional groups $[117,118]$, the enzymatic NC production is commonly regarded as a highly selective and specific method [10]. Proper control of the enzyme dosage as well as the operational conditions and the composition of the enzymes cocktail, can allow a high process control, not only of the levels of degradation of the different solid components but also of the properties of the final material [103]. One of the main benefits from this control is the ability to prevent an extensive/thorough hydrolysis of cellulose $[48,103]$, which would affect the extraction yield, but also the possibility to recover a clean sugar stream that can be easily used to produce value-added compounds [45]. The enzymatic extraction typically causes a decrease in the degree of polymerization and an increase of the crystallinity index, as a result of the hydrolysis of amorphous regions [119]. Another common advantage refers to a final NC product with a higher aspect ratio, as already observed by several authors $[6,85,120]$.

A final aspect to also consider is that enzymatic extraction does not modify the surface chemistry of cellulose since no additional charges are introduced [103], usually resulting in a material with higher thermal stability $[47,54,121]$. As compared to sulfuric acid hydrolysis, this represents a clear advantage since the presence of sulfur groups leads to a negative surface charge [122].

\subsubsection{Economic Improvements}

A most relevant aspect to consider on enzymatic NC production is the economics of the overall process, whether the enzymatic treatment represents a more economical option or is still not consensual. Adding to the economic benefits referred above and coming from an operation under mild conditions and a reduced chemicals utilization, the application of an enzymatic treatment will facilitate either the mechanical fibrillation or the production of $\mathrm{CNCs}$, reducing the energy requirements to produce the same amount of NC material. While these benefits from enzymes are consensual, there is a clear lack of accurate estimations of the putative energetic savings introduced by enzymes. As pointed out by Rol et al. [51], this comparison should be carefully conducted since distinct extraction processes may produce NC particles with different modification rates and dimensions. A recent study by Espinosa et al. [25], employing an extrusion process after hydrolysis, reported a reduction of $37 \%$ of the energy consumption. In addition, Rol et al. [51] observed that the energy consumed to produce CNFs by extrusion (seven passes) decreased from over $15,000 \mathrm{kWh} / \mathrm{t}$ to approximately $5000 \mathrm{kWh} / \mathrm{t}$ when enzymes were employed; similar estimations of this type are, however, scarce.

On an opposite side, some authors have also pointed out that because of the cost of enzymes, which remains very high [123], this technology is still not very attractive from an economic point of view [13,22]. Nevertheless, as it may be possible to totally/partially reuse enzymes $[58,124]$, it is conceivable to some extent that this cost could be tackled in the near future.

\section{Nanocellulose Properties}

\subsection{Morphology and Size}

NC morphology is strongly influenced by the production method, treatment conditions (e.g., treatment time, temperature, etc.), as well as by the source $[125,126]$. CNFs have a filament-like structure. They are long and flexible nanofibrils, consisting of both crystalline and amorphous domains. A CNF network can be seen as a nanoporous web-like structure of highly entangled nanofibers. On the other hand, CNCs are generally rigid needle- or rod-like nanoparticles obtained from crystalline parts of cellulose fibers [9,127]. Spherical CNCs have been reported in some works [48,64,76,86,128,129], and seem to be related to the higher severity of the process, such as high enzyme load. 
Typically, CNFs present a high aspect ratio with a diameter less than $100 \mathrm{~nm}$ and a length of a few micrometers, depending on the production method [126,127]. Generally, CNCs diameter can vary from 10 to $50 \mathrm{~nm}$ and around 100 to $500 \mathrm{~nm}$ in length depending on the source [127]. Table 3 presents the sizes of CNFs and CNCs obtained from BEKP treated by enzymatic hydrolysis and other production methods, and as observed, CNCs from enzymatic hydrolysis have shown a greater length, as well as diameter, than those usually described for CNCs.

As previously referred, CNFs generally are produced by mechanical disintegration of the cellulosic fiber suspension under high shear forces, causing a longitudinal cleavage of the cellulose fibers into nanofibrils, while CNCs are usually produced by acid hydrolysis, typically with concentrated sulfuric acid under strictly controlled conditions, which after some kind of mechanical dispersion (i.e., sonication) yields nanocrystals. Currently, the enzymatic treatment has been used as an alternative or combined with a mechanical treatment aiming to decrease the energy spending of mechanical processes, which have high energy consumptions [127]. It has also been a greener alternative to acid hydrolysis since it operates under mild reaction conditions and without the generation of hazardous waste, as well as less water spent and processing steps. Furthermore, it allows recovering the hydrolysis products as a clean sugar stream, due to the specificity of the enzymes, which can be used to produce several value-added products $[45,130]$. In addition, the yields and morphologies of CNCs and CNFs can be tailored by controlling certain reaction conditions [11].

CNCs isolated by enzymatic hydrolysis have a higher aspect ratio $(\mathrm{L} / \mathrm{D})$ than that from acid hydrolysis [45,131]. Tibolla et al. [81] recovered CNFs with a higher aspect ratio $(353.9 \pm 28.2$, being $7.6 \pm 1.5 \mathrm{~nm}$ diameter and $2889.7 \pm 214.3 \mathrm{~nm}$ length) from enzymatic treatment than from chemical treatment ( $42.7 \pm 7.5$, being $10.9 \pm 2.3 \mathrm{~nm}$ diameter and $454.9 \pm 6.6 \mathrm{~nm}$ length). On the other hand, Ma et al. [70] recovered CNCs from enzymatic hydrolysis with higher dimensions $(28.4 \pm 2.1 \mathrm{~nm}$ diameter and $343 \pm 27 \mathrm{~nm}$ length) comparatively to acid hydrolysis (18.2 $\pm 1.9 \mathrm{~nm}$ diameter and $274 \pm 32 \mathrm{~nm}$ length), but with a lower aspect ratio.

Table 3. Size of NC obtained from bleached eucalyptus Kraft pulp (BEKP) from enzymatic treatment and other production methods.

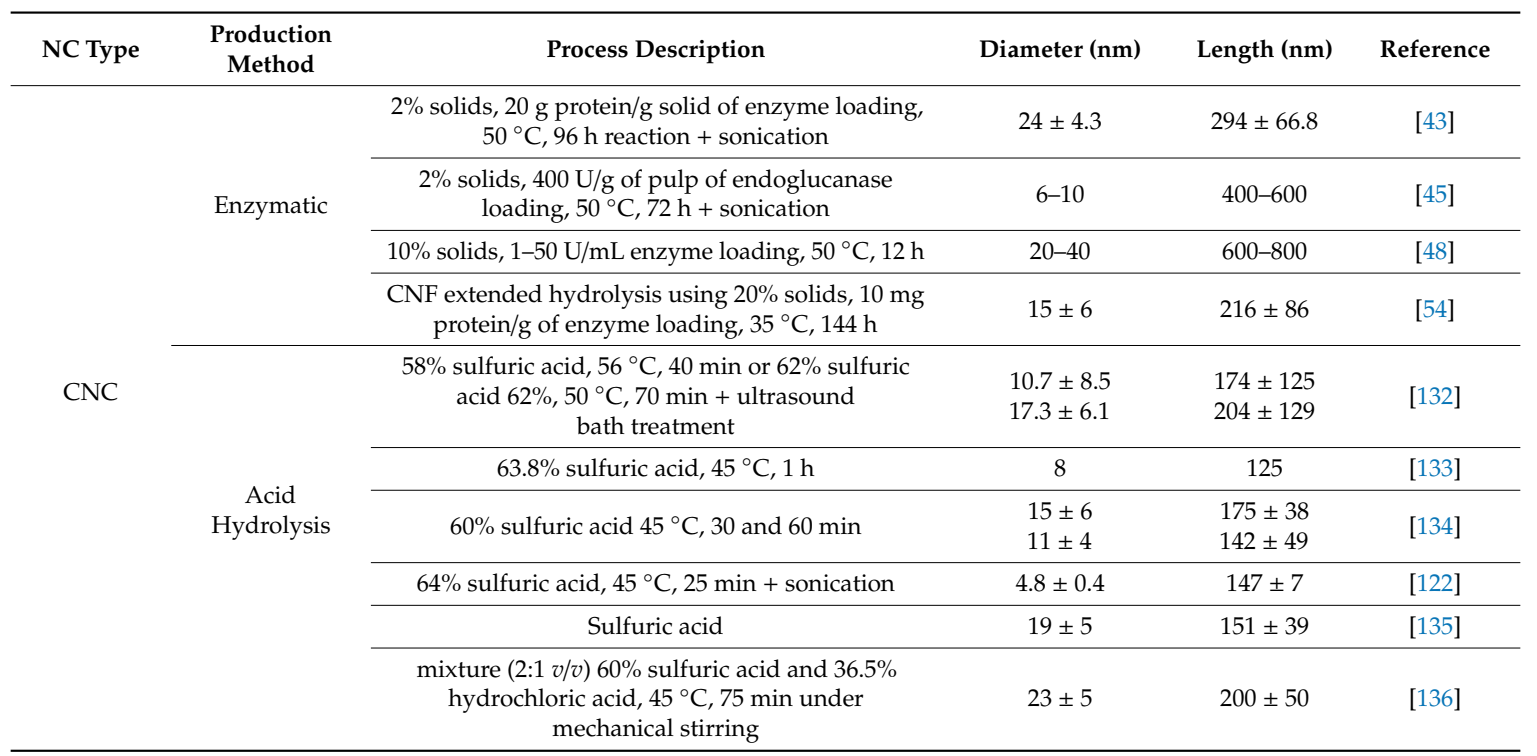


Table 3. Cont.

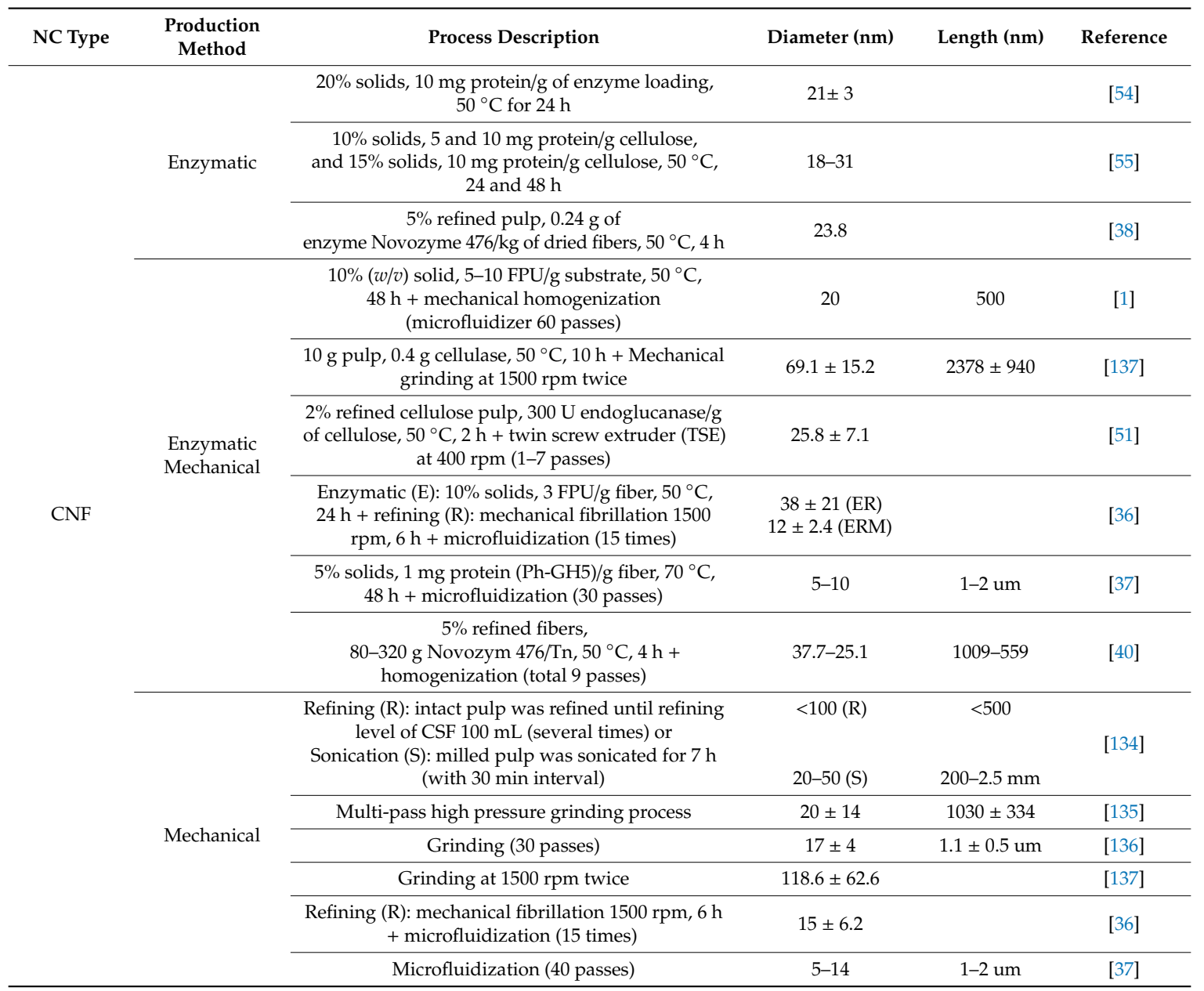

A previous step of enzymatic hydrolysis before the mechanical treatment has also shown to recover more uniform CNFs than only mechanical treatment, as reported by Zhu et al. [1], Qing et al. [36], Wang et al. [37], and Chen et al. [137]. Zhu et al. [1] verified that cellulase reduced the fiber length, resulting in CNFs with good uniformity in length. Wang et al. [37] also verified that a step of enzymatic hydrolysis previous to the mechanical fibrillation (microfluidization) allowed to obtain CNFs with the same length, but slightly thinner (lower diameter) and more uniform, while it also decreased the number of passes in the mechanical process, suggesting mechanical energy savings of at least $30 \%$ for nanofibrillation of cellulosic fibers.

\subsection{Crystallinity and Polymerization Degree}

During the process of NC production, the disordered amorphous regions of cellulose are removed resulting in the increase of the crystallinity [126,131], and depending on the treatment used or the suitable combination of them, NC with different degrees of crystallinity are obtained [34]. The length of the microfibrils is related to the degree of polymerization (DP) of constitutive cellulosic chains or molecular weight, and depending on the enzyme hydrolysis process before fibrillation, cellulosic chains with different DPs can also be obtained [131].

Zhu et al. [1] followed the crystallinity and polymerization degree of cellulose pulp during $72 \mathrm{~h}$ enzymatic hydrolysis and verified that crystallinity index (CI) increased from $46 \%$ to $57 \%$ (an increase of $24 \%$ ) after $48 \mathrm{~h}$ of hydrolysis. Significant reductions in DP throughout the hydrolysis process were also observed due to the action of cellulases, that not only hydrolyzed the cellulose chain but also significantly reduced the fiber length (from $1.2 \mathrm{~mm}$ to $200 \mu \mathrm{m}$ ) after $24 \mathrm{~h}$ hydrolysis, resulting 
in a substrate with good uniformity in length. A decrease in the DP was also observed by Tarrés and co-authors [39] by increasing the enzyme load and the hydrolysis time.

The crystallinity study of the produced NC is important to understand the effect of production methods on the crystal structure of NC. In addition, by increasing the severity of the hydrolysis (increasing the hydrolysis time or enzyme load), it is possible to depolymerize the crystalline cellulose, decreasing the length of the particles, and their aspect ratio, and eventually resulting in spherical particles [138]. Tong et al. [48] and Chen et al. [64] reported the production of spherical CNCs by increasing the enzyme load. De Aguiar et al. [11] studied the production of CNCs from sugarcane bagasse and straw and verified an increase in the CI of CNCs obtained after $24 \mathrm{~h}$ of enzymatic hydrolysis, indicating that enzymes acted on the removal of amorphous regions of cellulose. However, as hydrolysis time increased, there was a slight decrease of $\mathrm{CI}$, which could indicate that the enzymes started to depolymerize the crystalline regions of cellulose. The increase of the hydrolysis severity also led to lower CNC dimensions (length and diameter). Cui et al. [47] verified a decrease in CI at the highest severity condition that corresponded to $120 \mathrm{~h}$ hydrolysis and $60 \mathrm{~min}$ ultrasonic treatment.

\subsection{Mechanical Properties}

CNFs present a dense network held together by strong interfibrillar bonds, resulting in enhanced mechanical properties. This is related to the relatively high crystallinity of NC, the abundance of hydroxyl groups on their surface, and the high aspect ratio that promotes this reinforced structure $[4,127]$. Crystallinity and polymerization degree influence the physical properties of nanofibrillated cellulose matrix, wherein a high DP of cellulose leads to films with higher tensile strength $[9,16,34]$. The aspect ratio presents an important role in determining the nanofiber's reinforcing capacity, as it affects the fiber's ability to maintain the film network [53]. Moreover, the high surface area of the CNC also induces great mechanical properties [127].

$\mathrm{CNFs}$ and $\mathrm{CNCs}$ have a higher axial elastic modulus and tensile strength compared to the synthetic fiber Kevlar that is used commercially to reinforce plastics. In general, their mechanical properties are within the range of materials used as reinforcement, such as carbon fiber. These characteristics are attributed to their crystalline regions, appearing as a bundle of stretched cellulose chain, with axial elastic modulus values ranging between 110 and 220, tensile strength up to $7.7 \mathrm{GPa}$, and a density of $1.6 \mathrm{~g} / \mathrm{cm}^{3}[9,34,138]$.

Several works have investigated the mechanical properties of NC composites. Xu et al. [135] compared the incorporation of CNCs and CNFs on polyethylene oxide (PEO) films and verified that, for the same NC concentration, CNFs led to higher strength and modulus than CNCs due to the higher aspect ratio of CNFs and to the entanglement of fibers, but with less strain-at-failure due to their relatively large fiber clusters. Tibolla et al. [57] prepared nanocomposite films with CNFs from enzymatic hydrolysis, verifying that these had lower elongation at break and higher Young's modulus and tensile strength than the control film. The most affected property by CNFs was Young's modulus, due to an increase in more than $100 \%$ with the incorporation of CNFs. In addition, the films reinforced with CNFs1 $(\mathrm{L} / \mathrm{D}=404.5)$ were more rigid and brittle than that with $\mathrm{CNFs} 2(\mathrm{~L} / \mathrm{D}=170.2)$, suggesting that the aspect ratio of the nanofibers might be a parameter influencing the mechanical properties of films. CNFs1 presented lower length and diameter $(1490 \pm 107.3 \mathrm{~nm}$ and $3.7 \pm 0.4 \mathrm{~nm})$ than CNFs2 $(1544.5 \pm 40.6 \mathrm{~nm}$ and $8.8 \pm 0.7 \mathrm{~nm})$; thus, CNFs number per unit area in the films could explain the arrangement of a more homogeneous, interconnected, and rigid structure with a reduction of CNFs1 film elongation, suggesting that mechanical properties of films seem to be affected by the size of CNFs.

Zhao and co-authors [139] verified that by varying the content of CNFs on all cellulose nanocomposite films, Young's modulus of the nanocomposite films increased from $0.76 \mathrm{GPa}$ to 4.16 GPa and the tensile strength from 61.56 MPa to 99.92 MPa. Zhu et al. [1] produced films using CNFs obtained through enzymatic hydrolysis + microfluidization and verified that the tensile strength (maximum stress) of the CNF film was $45 \pm 5 \mathrm{MPa}$, or more than an order of magnitude greater than 
sheets made with the control fibers $(3.7 \pm 0.3 \mathrm{MPa})$. The modulus of the CNF film was $5400 \pm 180 \mathrm{MPa}$, or about six times of the sheet made from the control fibers ( $900 \pm 60 \mathrm{MPa})$. Control films corresponded to pure hydrolyzed fibers with no microfluidization, showing that the mechanical treatment after the enzymatic hydrolysis was important to enhance the mechanical properties of films.

On the other hand, Zhao et al. [74] compared the mechanical properties of softwood CNFs from TEMPO-mediated oxidation ( $\mathrm{tSW}$ ) and enzymatic hydrolysis (eSW), as well as the hardwood CNFs from enzymatic hydrolysis (eHW), verifying that the tensile stress of tSW and eSW was similar (81.8 and 79.0 MPa), while the modulus was significantly higher for tSW (10.6 GPa) comparatively to eSW (5.8 GPa). The authors attributed this result to the introduction of anionic charged carboxyl groups that could induce the formation of additional hydrogen bonds to those from the original hydroxyl groups, hence contributing to more inter-fiber bonding and thus a stronger network. Another possible explanation suggested by the authors was that the tCNFs are more evenly distributed prior to the film formation, and thus fewer "weak points" are formed. Moreover, films from softwood (eSW) were slightly stronger than those from hardwood (eHW), as seen by the tensile stress of 79.0 vs. 69.0 MPa and Young's modulus of 5.8 GPa vs. 4.6 GPa. The strength of a film showed to be closely correlated to the DP, crystallinity, and aspect ratio of the CNFs used. In addition, Tarrés et al. [40] compared the mechanical properties of nanopapers produced from TEMPO-mediated oxidation CNFs (CNFs-T) and enzymatic CNFs (CNFs-E) and verified that CNFs-E were weaker at tensile than CNFs-T, but with similar stiffness levels. According to the authors, the strength differences of nanopapers from CNFs-T and CNFs-E are probably due to the differences in the intrinsic properties of each CNF, such as higher specific surface and fibrillation yield for CNFs-T, a condition that gives CNFs-T a greater swelling capacity and, therefore, better ability to form a three-dimension network.

\subsection{Thermal Properties}

Thermal stability is an important property for NC since the processing temperatures of most composite materials are usually above $200{ }^{\circ} \mathrm{C}[43,54]$. Cellulosic materials degrade below $400{ }^{\circ} \mathrm{C}$ (generally decomposition starts at $310^{\circ} \mathrm{C}$ and persists until $400{ }^{\circ} \mathrm{C}$ ) [53], with the degradation temperature dependent on the structure and chemical composition [126].

It has been shown that the particle size and the pretreatment used to obtain the cellulosic material affect the thermal properties. As a result, CNFs start to decompose at a higher temperature $\left(350{ }^{\circ} \mathrm{C}\right)$ than CNCs (thermal degradation starts typically between 200 and $300^{\circ} \mathrm{C}$ ) $[28,125]$. Reduced thermal stability of CNCs is related to sulfuric acid hydrolysis that results in CNCs with high colloidal stability, due to the introduction of negatively-charged sulfate groups, but also in a significantly lower thermal stability, which limits several applications requiring high temperatures for processing $[3,43,45]$. The sulfate groups degrade around $120^{\circ} \mathrm{C}$ and they decrease the thermal stability of cellulose [126]. CNCs with lower sulfate content have better thermal stability [125], which can also be increased by neutralizing the sulfate groups [140].

On the other hand, CNCs produced by enzymatic hydrolysis present a high number of free hydroxyls on their surface that can interact strongly among each other through hydrogen bonds and van der Waals forces, which can confer low colloidal stability regarding CNCs produced by sulfuric acid, but higher thermal stability $[45,121,130]$. Therefore, enzymatic hydrolysis offers an attractive way to produce NCs with superior thermal stability, contributing to further expansion of their range of applications $[43,141]$.

Squinca et al. [43] observed that CNCs produced from enzymatic treatment presented higher thermal stability regarding the mechanical one, attributing this finding to the increased crystallinity. In addition, De Aguiar et al. [11] verified an increase of the thermal stability of CNCs produced by enzymatic hydrolysis (Tonset at $\sim 310^{\circ} \mathrm{C}$ ) when compared to the crude and treated fibers. However, by increasing the hydrolysis time, the thermal stability of the fibers decreased, which may be related to a reduction in the size of the nanoparticle, which was observed with the extended time of hydrolysis, or to the decrease in CI as well. On the other hand, Chen et al. [64] produced rod-like and spherical 
CNCs, according to the enzyme load, and reported similar thermal stability (Tonset at $\sim 205^{\circ} \mathrm{C}$ and Tmax at $\sim 345^{\circ} \mathrm{C}$ ). Furthermore, Bondancia and co-authors [54] reported that CNFs and CNCs obtained by enzymatic hydrolysis presented superior thermal stability compared to materials obtained by means of chemical hydrolysis reactions. They reported degradation of cellulose pulp at $331{ }^{\circ} \mathrm{C}, \mathrm{CNFs}(24 \mathrm{~h})$ at $323{ }^{\circ} \mathrm{C}$, and $\mathrm{CNCs}(144 \mathrm{~h})$ at $325^{\circ} \mathrm{C}$. Lastly, Zhao et al. [74] observed that CNFs from enzymatic hydrolysis had higher thermal stability than CNFs from TEMPO-mediated oxidation.

\subsection{Barrier Properties}

Nanocellulose research involving barrier properties has mainly focused on water vapor and oxygen permeabilities. Cellulose is a hydrophilic polymer, absorbing water when subjected to a moisture atmosphere, however, a decrease in water vapor permeability (WVP) has been seen for nanoscale cellulose $[4,142]$. The barrier properties of nanocellulose are related to its relatively high crystallinity, associated with its capacity to form a dense network held together by strong interfibrillar bonds, which make diffusion of molecules in the crystalline domains of cellulose fibrils difficult [4,143].

The barrier properties have been studied mainly for MFC films that have shown outstanding performance. Belbekhouche et al. [143] studied the influence of the nature of the nanoparticles (CNC and MFC) on the barrier properties of the films, that is, WVP and gas (carbon dioxide, nitrogen, and oxygen) permeability. Surprisingly, CNC films presented higher water vapor sorption than MFC films. Once CNC presented a more organized structure and highly crystalline structure than MFC, the authors attributed this result to the presence of residual lignin, extractives, and fatty acids at the surface of MFCs, which could result in MFC films with higher hydrophobicity. CNC films also presented higher permeability to gases than MFCs, showing that other factors, such as the highest porosity of the CNC films and the MFC's entangled structures that lead to an increase in the tortuosity of the diffusion path, may have a greater influence on the barrier properties than the crystallinity.

Other works have related the dependence of barrier properties of MFCs, mainly WVP, with different factors, such as MFC source, production method, and chemical modification of MFCs [16]. Spence et al. [144] produced MFCs from different wood pulp sources (bleached softwood and hardwood, and unbleached ones containing or not lignin), and compared the water vapor transmission rate (WVTR) of MFC films with the source and chemical composition. They compared the WVTR of the original pulps with those of the corresponding MFCs and verified that the processing to convert the macrofibrils into MFCs resulted in a decrease in the WVTR (from 20\% to 30\%). MFCs from bleached hardwood presented the highest water vapor barrier $\left(200 \mathrm{~g} / \mathrm{m}^{2} /\right.$ day) among the different sources, and the lignin-containing sources presented higher WVTR, which may be due to the larger pores in the films (from $300 \mathrm{~g} / \mathrm{m}^{2} / \mathrm{day}$ to $460 \mathrm{~g} / \mathrm{m}^{2} /$ day). Thus, the chemical composition of wood pulps appears to have a greater effect on water barrier properties than the type. Minelli et al. [142] prepared MFC-based films using two kinds of MFCs, with similar source and composition, but with two different processing methods, that is, enzymatic treatment (MFC G1) and carboxymethylation treatment (MFC G2); both were followed by high-pressure homogenization, resulting in MFCs with different dimensions (17-30 nm diameter MFC G1 and 5-15 nm MFC G1) and anionic charge densities ( 40 mequiv./g for MFC G1 and 586 mequiv./g for MFC G2). Carboxymethylated MFC films presented a more compacted nanofibril network (as reveled by FE-SEM images) and lower WVP than the enzymatic MFC films, however, the differences were small, suggesting that the treatment did not play an important role in water vapor properties.

Moreover, the physical structure of the MFCs also affects the WVP of the films [16]. Tibolla et al. [57] incorporated CNFs (also designated MFCs) isolated through enzymatic hydrolysis on starch-based films and verified that water barrier properties were dependent on the CNFs size and aspect ratio. Films produced with CNF1 showed a reduction in WVP, while CNF2-based films (higher diameter and length size, and then lower aspect ratio than CNF1) showed an increase. Longer CNFs tend to agglomerate, facilitating the water molecules' permeation through the polymer matrix gaps, while smaller CNFs are more properly dispersed into the matrix, showing that the poor performance of nanocellulose composites is also related to the poor dispersion of the filler. 
Nanocellulosic materials have been reported to present good oxygen barrier properties. Syverud and Stenius [145] reported a low oxygen transmission rate (OTR) for MFC films (17-18 mL/m²/day at $0 \% \mathrm{RH}$ (Relative humidity) for films $21-30 \mu \mathrm{m}$ thick), that was comparable to the synthetic PVdC-coated, oriented polyester $\left(9-15 \mathrm{~mL} / \mathrm{m}^{2} /\right.$ day), with similar thickness. The recommended OTR for modified atmosphere packaging is less than $10-20 \mathrm{~mL} / \mathrm{m}^{2} /$ day [146]. Fukuzumi et al. [147] reported a significant decrease in oxygen permeability at $0 \%$ RH of $25 \mu \mathrm{m}$ tick PLA (polylactic acid) film $\left(746 \mathrm{~mL} / \mathrm{m}^{2} /\right.$ day $\left./ \mathrm{Pa}\right)$, when it was coated by a thin $(0.4 \mu \mathrm{m}) \mathrm{TEMPO}-$ oxidized cellulose nanofiber (TOCN) layer $\left(1 \mathrm{~mL} / \mathrm{m}^{2} /\right.$ day $\left./ \mathrm{Pa}\right)$, making it, according to the authors, comparable to oxygen permeability of typical synthetic polymers that have high oxygen barrier property, such as poly(vinylidene chloride) and polyethylene-poly(vinyl alcohol) copolymers. Similar behavior was observed by Rodionova et al. [148] for PET (polyethylene terephthalate) films coated by TOCN.

The low permeability to oxygen of the nanocellulose, in dry conditions $(0 \% \mathrm{RH})$, is related to its high crystallinity and dense structure. However, its performance is strongly limited by its hygroscopic properties and consequent moisture sorption, which creates less packed films, reducing the barrier with higher relative humidity, as verified by Minelli et al. [142], who reported that MFC films also showed excellent oxygen barrier properties in dry conditions. However, in wet conditions, MFC films showed an increase in permeability, as observed for hydrophilic molecules. Chemical modification on MFC (i.e., carboxymethylation) was developed by Aulin et al. [149] to improve the oxygen barrier properties of nanocellulose films at high RH level.

\subsection{Optical Properties}

The influence of cellulose structures on optical properties of composites is related to different characteristics such as size, shape, ordering, charge, and dispersity of the cellulosic material into the matrix [150]. Additionally, NC concentration in the composite and its thickness can affect the transmittance and clarity of the final material [34].

CNFs possess great optical properties, considering the size of the CNFs is less than the wavelength of visible light [126,151]. Films prepared with CNFs appear smoother and less porous than the traditional cellulosic papers and have a certain level of transparency (light transmission) depending on the CNF dimensions. On the other hand, CNCs can organize themselves in a chiral nematic way in suspensions leading to the formation of iridescent films once dried, unlike CNFs [152]. However, even though the films produced by CNCs are transparent, they are usually more brittle than those of CNFs due to their crystalline nature [127].

$\mathrm{Xu}$ and co-authors [135] showed that $\mathrm{PEO} / \mathrm{CNC}$ films exhibit higher transparency than $\mathrm{PEO} / \mathrm{CNF}$ films, most likely due to $\mathrm{CNCs}^{\prime}$ smaller sizes and lack of agglomeration and entanglement. Tarrés et al. [39] observed that the transmittance of the CNFs in general increased with the increase of the enzyme load and hydrolysis time, which are related to the higher yields of nanofibrillation. Furthermore, Zhu et al. [1] produced films using CNFs obtained through enzymatic hydrolysis + microfluidization and verified that the opacity of the films clearly decreased with the number of passes through the microfluidizer, where films produced from highly nanofibrillated cellulose (60 passes) had opacity values of only approximately $12 \%$. On the other hand, CNFs produced from TEMPO-mediated oxidation showed much higher transmittance than those from enzymatic hydrolysis $[38,40,74]$. According to the authors, this could be related to the introduction of surface charge on TEMPO-CNFs, which improves cellulose disintegration resulting in more elementary fibrils, resulting in films more uniform and of higher density, as well as with a higher diameter and lower fibrillation yield of enzymatic CNFs.

\subsection{Rheological Properties}

As a final point, rheological studies can give information about the fibrillation state of the particles [131]. Some cellulose-based structures present interesting rheological properties that can be described in terms of pseudo-plasticity and shear-thinning behavior [34]. The particularity of NC 
is that their dispersions present unusual rheological properties [153]. These NC particles are able to immobilize a high amount of water into developed external and internal surfaces with the production of highly viscous gel-like water systems [4].

Pääkkö et al. [63] studied the rheological behavior of enzymatically treated MFC and the relation between this behavior and the mechanical properties of these materials. The study showed that MFC suspensions displayed a gel-like behavior from concentrations of $0.125 \%$ to $5.9 \%$. The values of the storage modulus $\left(\mathrm{G}^{\prime}\right)$ were rather high; about $10^{4} \mathrm{~Pa}$ was reported for a $3 \% \mathrm{MFC}$ suspension, as compared to $10^{2} \mathrm{~Pa}$ reported previously by Tatsumi et al. [154] for a 3\% suspension of rod-like CNCs. In addition, the storage modulus was particularly dependent on the MFCs' concentration, where increasing MFCs' concentration from $0.125 \%$ to $5.9 \%$ resulted in an increase in the storage modulus by five orders of magnitude. The authors attribute this high elastic modulus to the long fibrils and fibrils aggregates, which form an inherently entangled network structure.

On the other hand, Tang et al. [65] studied the rheological behavior of CNC suspensions obtained from acid hydrolysis/sonication process, acid hydrolysis/enzymatic hydrolysis $(1 \mathrm{~h}) /$ sonication process, and acid hydrolysis/enzymatic hydrolysis $(24 \mathrm{~h})$ /sonication process. All CNC suspensions exhibited a visible shear-thinning behavior; however, the CNCs from enzymatic hydrolysis treatment presented a strong reduction in viscosity, which may be related to the progressive removal of amorphous regions of cellulose, leading to a reduction in DP. In addition, as the angular frequency increased, the storage modulus of CNC suspensions increased, although this increase was less evident with the increase in enzymatic hydrolysis time, indicating a gel-like behavior due to the high aspect ratio of the nanofibril gelation network, as suggested by the authors.

\section{Market and Applications}

The nanoscale dimensions, high aspect ratio, and outstanding reinforcing potential of NC have increased the demand for NC to be used in nanocomposites. The market for NC is expected to grow from 297 million USD in 2020 to 783 million USD by 2025, at a compound annual growth rate (CAGR) of $21.3 \%$. Pulp and paper represent the majority of the overall market, being used as additives in papermaking to produce lighter and stronger paper and board providing improved properties, such as less porosity, higher printing quality, and less transparency [155].

Recently, NC has attracted a lot of attention as a potential filler in nanocomposites (Figure 4). It has been reported that the incorporation of $\mathrm{NC}$ in a wide range of polymer matrices improves their mechanical properties. Table 4 reports the applications of NC produced by enzymatic hydrolysis in different fields. In the food industry, NC has been incorporated in a polymer matrix to improve the mechanical properties of the nanocomposite to be used as coating and films in food packaging, providing protection to ensure food safety and quality, and shelf life of perishable foods. NC films also show excellent oxygen barrier properties related to the high crystallinity, a network structure held together through strong inter- and intramolecular hydrogen bonds, a lamellar nanofiber structure, and dense fiber bundles [156-158]. CNFs have also been used as filler in all-cellulose nanocomposite films [139,159]. In addition, NC, as a dietary fiber, can be used in functional foods to reduce the risk of chronic diseases such as diabetes, obesity, cardiovascular disease, and diverticulitis. It also fosters beneficial physiological effects, such as laxation and attenuation of blood cholesterol and glucose and has been explored to produce reduced-fat foods to treat weight disorders. NC based-hydrogels have also been applied for delivery of nutrients or bioactive compounds, protecting the stored compound and controlling their release into the gastrointestinal system [160]. NC can also be used as thickeners and suspension emulsifiers and stabilizers in a wide variety of food products (food additives) [156-158]. Recently, VTT produced cellulose-based materials from enzymatic fibrillated cellulose (HefCel) technology. These HefCel CNFs can be used as reinforcement of paper and packaging materials [161]. 

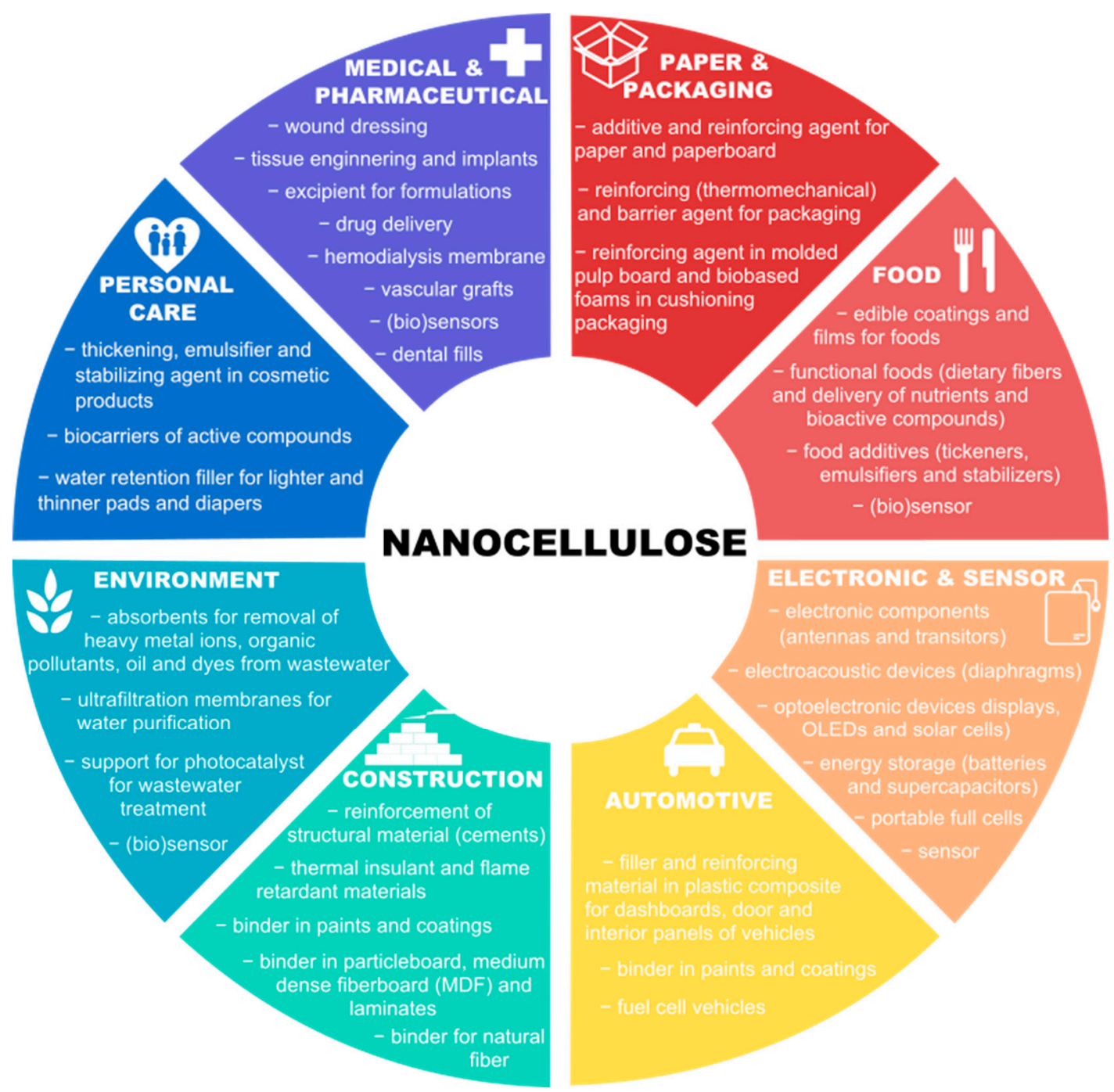

Figure 4. The potential application of nanocellulose in different fields.

NC has shown great potential in electronic applications. NC has been used as a flexible and transparent substrate, such as paper and polymer films, for the development of flexible electronic devices, such as solar cells, sensors, and flexible displays. CNFs have been the most used substrate in electronic devices rather than CNCs probably due to the more brittle nature of CNCs than CNF films, which makes them more suitable for flexible substrates. NC is also a promising bio-based material in the synthesis of conductive materials as it can act as (i) a bio-template for the synthesis of tubular conductive particles using $\mathrm{NC}$ with a high aspect ratio; (ii) a capping and nucleating agent in the synthesis of metallic particles; and (iii) a dispersing and stabilizing agent or (iv) a binding agent in ink formulation. It has been used for the fabrication of energy devices, such as batteries and supercapacitors [127,162]. Vilela et al. [163] revised the application of NC in polymer electrolyte fuel cells, namely the ion-exchange membrane and electrocatalyst, as well as in the application of NC-based components in microbial fuel cells (MFCs).

NC has also been applied in environmental remediation as a new generation of nanostructured adsorbents for different classes of pollutants due to their large surface area, vast surface hydroxyl groups, and their easy functionalization [111,164]. In general, these NC-based adsorbents need to pass by a surface functionalization process to be able to enhance their adsorption capacity and adsorb a specific class of pollutant [165]. NC-based adsorbents, such as aerogels, filtration membranes, porous beads, and flocculants, have been used for removal of heavy metal ions $\left(\mathrm{Cu}^{2+}, \mathrm{Pb}^{2+}, \mathrm{Hg}^{2+}\right)$, organic 
pollutants (pesticides such as DTT (dichlorodiphenyltrichloroethane), industrial chemicals such as PCBs (Polychlorinated biphenyls), and substances such as dioxins), dyes (methylene blue, Congo Red, rhodamine) and oils in water purification systems and wastewater treatment, and for removal of air contaminants.

In the biomedical field, CNC and CNF hydrogels have been used for many biomedical applications, such as wound dressing, drug delivery, and tissue engineering, due to their biocompatibility, biodegradability, mechanical properties, and the advantages of a nanostructure. In addition, NC has antimicrobial activity, wound healing properties, a non-toxic nature $[110,166]$, and also a high binding potential through the available $\mathrm{OHs}$ and negative interfacial charges, which make their electrostatic adsorption on tissues easier [167].

In wound dressing, NC provides a suitable environment for the wound healing process for burnings and wounds: it provides an infection barrier; absorbs the purulent fluids in exudative wounds; allows good oxygen permeability for cellular proliferation and to prevent the growth of anaerobic bacteria; keeps the wound surface moist; has a painkiller effect; and has a high degree of adherence to various types of tissues $[125,160]$. In addition, the translucency of CNFs helps to follow the development of the wound without the need to remove the dressing [168]. In drug delivery systems, it allows a controlled and sustained release profile. Drug carriers based on NC are generally classified in microparticles, hydrogels, gels, membranes, and films [110]. In recent years, stimuli-responsive CNF-based hydrogels received much attention, due to the drug-releasing performance under specific stimulus control, for example, $\mathrm{pH}$, temperature, and ionic strength [166]. CNC- and CNF-based hydrogels have been broadly used in tissue engineering in the last years due to their highly hydrated three-dimensional porous structure that mimics biological tissue, as well as their outstanding mechanical property $[166,169]$. Thus, much attention has been paid to the 3D printing technique for fabricating implants and scaffolds for tissue engineering applications $[111,166,170]$. Table 4 reports the application of NC produced by enzymatic hydrolysis in different fields.

Table 4. Application of nanocellulose in different fields.

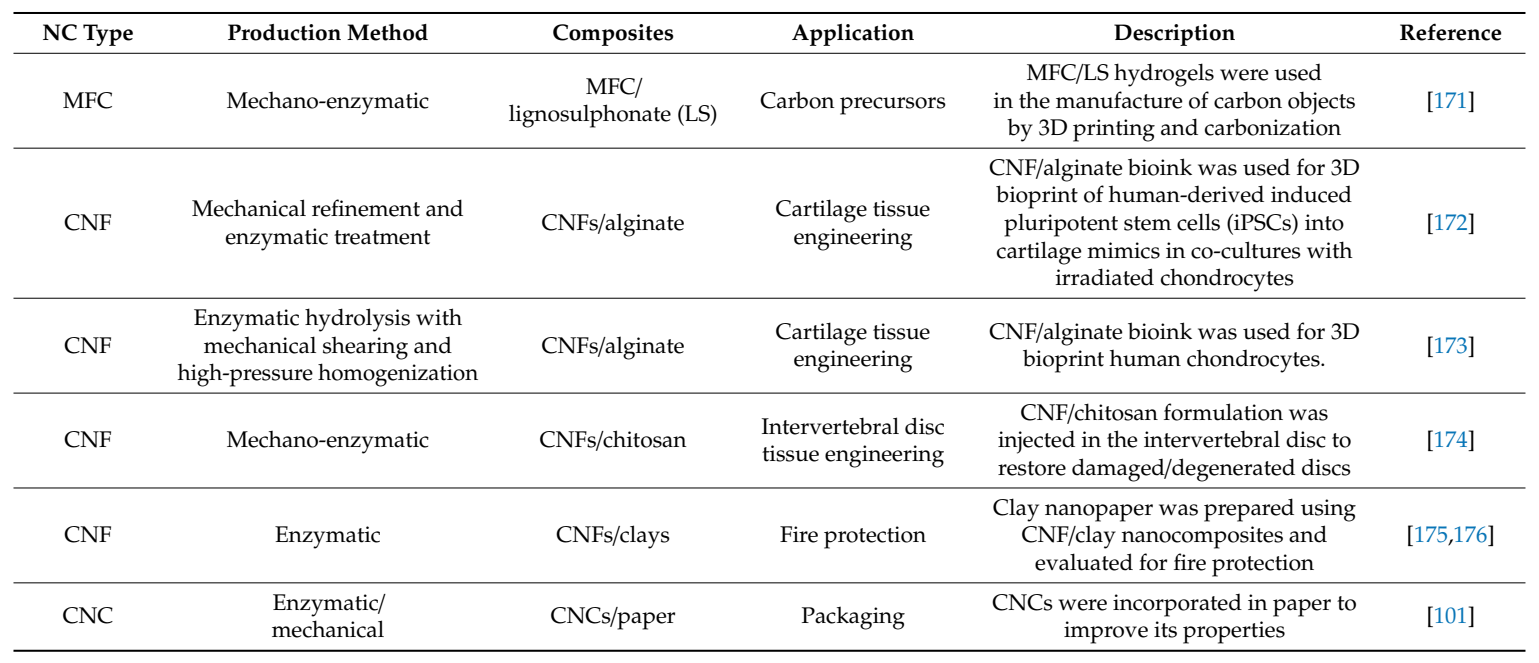

\section{Final Remarks}

The cost involving NC production still makes large-scale operations difficult. In recent years, the increasing search for environmentally friendly and biodegradable materials has driven the development of processes using enzymatic hydrolysis. The NC production by enzymatic treatment presents a viable alternative to scale-up the NC production, since it may contribute to decreasing the total cost of the process, as well as the environmental impact related to others production methods. NC production by enzymatic treatment presents several advantages, as discussed previously, namely mild reaction conditions, no production of hazardous waste, reduced consumption of water, 
and the possibility of using the secondary stream of fermentable sugars released in the hydrolysis to obtain other bio-based products. Moreover, NC production by enzymatic hydrolysis has been reported to result in easily functionalized nanostructures, with high thermal stability, specific surface area, and aspect ratios. Currently, enzymatic hydrolysis has been explored to decrease the energy requirement to obtain $\mathrm{CNF}$ via mechanical treatment or eliminate/minimize the use of hazardous chemicals, such as sulfuric acid and TEMPO. However, the cost of enzymes is one of the main factors that determine the economics of the production process.

The development of enzymes at a competitive cost of production is a challenge, and many efforts have been made in this regard by many research groups. It is estimated that the culture medium represents more than $50 \%$ of the total costs of enzyme production, with the carbon source as the most expensive component. Therefore, significant efforts have been made to genetically modify T. reesei in order to diversify the carbon sources that it can utilize for enzyme production. Recently, a research group reported the development of an industrially relevant cellulase production platform, using T. reesei RUT-C30 strain. In this work the implementation of some genetic modifications and the development of a process based on sugarcane molasses, a low cost and highly concentrated sugar-rich product that contains many vitamins and minerals, allowed to achieve $80.6 \mathrm{~g} / \mathrm{L}$ of cellulase, being the highest levels of cellulase reported experimentally to date for T. reesei. Moreover, the saccharification efficiency of the enzyme cocktail produced was similar to that of a cellulase preparation available on the market [177]. Thus, studies point to the economic viability of producing cellulases in the near future, and consequently the NC production by enzymatic hydrolysis.

Funding: This work was carried out at the Biomass and Bioenergy Research Infrastructure (BBRI)- LISBOA-01-0145-FEDER-022059, supported by Operational Programme for Competitiveness and Internationalization (PORTUGAL2020), by Lisbon Portugal Regional Operational Programme (Lisboa 2020) and by North Portugal Regional Operational Program (Norte 2020) under the Portugal 2020 Partnership Agreement, through the European Regional Development Fund (ERDF) and was supported by the Portuguese Foundation for Science and Technology (FCT) under the scope of the strategic funding of UIDB/04469/2020 and through Project EcoTech (POCI-01-0145-FEDER-032206/ FAPESP 2018/07522-6) and BioTecNorte operation (NORTE-01-0145-FEDER-000004) funded by the European Regional Development Fund under the scope of Norte2020-Programa Operacional Regional do Norte.

Conflicts of Interest: The authors declare no conflicts of interest.

\section{References}

1. Zhu, J.Y.; Sabo, R.; Luo, X. Integrated production of nano-fibrillated cellulose and cellulosic biofuel (ethanol) by enzymatic fractionation of wood fibers. Green Chem. 2011, 13, 1339-1344. [CrossRef]

2. Camargo, L.A.; Pereira, S.C.; Correa, A.C.; Farinas, C.S.; Marconcini, J.M.; Mattoso, L.H.C. Feasibility of manufacturing cellulose nanocrystals from the solid residues of second-generation ethanol production from sugarcane bagasse. Bioenergy Res. 2016, 9, 894-906. [CrossRef]

3. Habibi, Y.; Lucia, L.A.; Rojas, O.J. Cellulose nanocrystals: Chemistry, self-assembly, and applications. Chem. Rev. 2010, 110, 3479-3500. [CrossRef]

4. Bajpai, P. Pulp and Paper Industry-Nanotechnology in Forest Industry; Elsevier: Amsterdam, The Netherlands, 2017.

5. Eichhorn, S.J.; Dufresne, A.; Aranguren, M.; Marcovich, N.E.; Capadona, J.R.; Rowan, S.J.; Weder, C.; Thielemans, W.; Roman, M.; Renneckar, S.; et al. Review: Current international research into cellulose nanofibres and nanocomposites. J. Mater. Sci. 2010, 45, 1-33. [CrossRef]

6. García, A.; Gandini, A.; Labidi, J.; Belgacem, N.; Bras, J. Industrial and crop wastes: A new source for nanocellulose biorefinery. Ind. Crops Prod. 2016, 93, 26-38. [CrossRef]

7. Klemm, D.; Cranston, E.D.; Fischer, D.; Gama, M.; Kedzior, S.A.; Kralisch, D.; Kramer, F.; Kondo, T.; Lindström, T.; Nietzsche, S.; et al. Nanocellulose as a natural source for groundbreaking applications in materials science: Today's state. Mater. Today 2018, 21, 720-748. [CrossRef]

8. Kalia, S.; Dufresne, A.; Cherian, B.M.; Kaith, B.S.; Avérous, L.; Njuguna, J.; Nassiopoulos, E. Cellulose-based bio- and nanocomposites: A review. Int. J. Polym. Sci. 2011, 2011, 837875. [CrossRef]

9. Brinchi, L.; Cotana, F.; Fortunati, E.; Kenny, J.M. Production of nanocrystalline cellulose from lignocellulosic biomass: Technology and applications. Carbohydr. Polym. 2013, 94, 154-169. [CrossRef] 
10. Yarbrough, J.M.; Zhang, R.; Mittal, A.; Vander Wall, T.; Bomble, Y.J.; Decker, S.R.; Himmel, M.E.; Ciesielski, P.N. Multifunctional cellulolytic enzymes outperform processive fungal cellulases for coproduction of nanocellulose and biofuels. ACS Nano 2017, 11, 3101-3109. [CrossRef]

11. De Aguiar, J.; Bondancia, T.J.; Claro, P.I.C.; Mattoso, L.H.C.; Farinas, C.S.; Marconcini, J.M. Enzymatic deconstruction of sugarcane bagasse and straw to obtain cellulose nanomaterials. ACS Sustain. Chem. Eng. 2020, 8, 2287-2299. [CrossRef]

12. Tibolla, H.; Pelissari, F.M.; Rodrigues, M.I.; Menegalli, F.C. Cellulose nanofibers produced from banana peel by enzymatic treatment: Study of process conditions. Ind. Crops Prod. 2017, 95, 664-674. [CrossRef]

13. Ribeiro, R.S.A.; Pohlmann, B.C.; Calado, V.; Bojorge, N.; Pereira, N. Production of nanocellulose by enzymatic hydrolysis: Trends and challenges. Eng. Life Sci. 2019, 19, 279-291. [CrossRef]

14. Pirich, C.L.; Picheth, G.F.; Fontes, A.M.; Delgado-Aguilar, M.; Ramos, L.P. Disruptive enzyme-based strategies to isolate nanocelluloses: A review. Cellulose 2020, 27, 5457-5475. [CrossRef]

15. Phanthong, P.; Reubroycharoen, P.; Hao, X.; Xu, G.; Abudula, A.; Guan, G. Nanocellulose: Extraction and application. Carbon Resour. Convers. 2018, 1, 32-43. [CrossRef]

16. Lavoine, N.; Desloges, I.; Dufresne, A.; Bras, J. Microfibrillated cellulose-Its barrier properties and applications in cellulosic materials: A review. Carbohydr. Polym. 2012, 90, 735-764. [CrossRef]

17. Faruk, O.; Bledzki, A.K.; Fink, H.P.; Sain, M. Biocomposites reinforced with natural fibers: 2000-2010. Prog. Polym. Sci. 2012, 37, 1552-1596. [CrossRef]

18. García, A.; Labidi, J.; Belgacem, M.N.; Bras, J. The nanocellulose biorefinery: Woody versus herbaceous agricultural wastes for NCC production. Cellulose 2017, 24, 693-704. [CrossRef]

19. Eugenio, M.E.; Ibarra, D.; Martín-Sampedro, R.; Espinosa, E.; Bascón, I.; Rodríguez, A. Alternative raw materials for pulp and paper production in the concept of a lignocellulosic biorefinery. In Cellulose; Pascual, A.R., Martín, M.E.E., Eds.; Springer: Berlin, Germany, 2019.

20. Sharma, D.; Chaudhary, R.; Kaur, J.; Arya, S.K. Greener approach for pulp and paper industry by Xylanase and Laccase. Biocatal. Agric. Biotechnol. 2020, 25, 101604. [CrossRef]

21. Chaurasia, S.K.; Bhardwaj, N.K. Biobleaching-An ecofriendly and environmental benign pulp bleaching technique: A review. J. Carbohydr. Chem. 2019, 38, 87-108. [CrossRef]

22. Kumar, V.; Pathak, P.; Bhardwaj, N.K. Waste paper: An underutilized but promising source for nanocellulose mining. Waste Manag. 2020, 102, 281-303. [CrossRef]

23. Pereira, B.; Arantes, V. Production of cellulose nanocrystals integrated into a biochemical sugar platform process via enzymatic hydrolysis at high solid loading. Ind. Crops Prod. 2020, 152, 112377. [CrossRef]

24. Reid, M.S.; Villalobos, M.; Cranston, E.D. Benchmarking cellulose nanocrystals: From the laboratory to industrial production. Langmuir 2017, 33, 1583-1598. [CrossRef] [PubMed]

25. Espinosa, E.; Rol, F.; Bras, J.; Rodríguez, A. Production of lignocellulose nanofibers from wheat straw by different fibrillation methods. Comparison of its viability in cardboard recycling process. J. Clean. Prod. 2019, 239. [CrossRef]

26. Frone, A.N.; Chiulan, I.; Panaitescu, D.M.; Nicolae, C.A.; Ghiurea, M.; Galan, A.M. Isolation of cellulose nanocrystals from plum seed shells, structural and morphological characterization. Mater. Lett. 2017, 194, 160-163. [CrossRef]

27. Santucci, B.S.; Bras, J.; Belgacem, M.N.; de Silva Curvelo, A.A.; Pimenta, M.T.B. Evaluation of the effects of chemical composition and refining treatments on the properties of nanofibrillated cellulose films from sugarcane bagasse. Ind. Crops Prod. 2016, 91, 238-248. [CrossRef]

28. Li, J.; Wang, Y.; Wei, X.; Wang, F.; Han, D.; Wang, Q.; Kong, L. Homogeneous isolation of nanocelluloses by controlling the shearing force and pressure in microenvironment. Carbohydr. Polym. 2014, 113, 388-393. [CrossRef]

29. Kwok, T.T.; Bright, J.R.; Vora, S.R.; Chrisandina, N.J.; Luettgen, C.O.; Realff, M.J.; Bommarius, A.S. Solvent selection for lignin value prior to pulping. ChemSusChem 2020, 13, 267-273. [CrossRef]

30. Tripathi, S.K.; Bhardwaj, N.K.; Roy Ghatak, H. Developments in ozone-based bleaching of pulps. Ozone Sci. Eng. 2020, 42, 194-210. [CrossRef]

31. Peretz, R.; Sterenzon, E.; Gerchman, Y.; Kumar Vadivel, V.; Luxbacher, T.; Mamane, H. Nanocellulose production from recycled paper mill sludge using ozonation pretreatment followed by recyclable maleic acid hydrolysis. Carbohydr. Polym. 2019, 216, 343-351. [CrossRef] 
32. Romaní, A.; Larramendi, A.; Yáñez, R.; Cancela, Á.; Sánchez, Á.; Teixeira, J.A.; Domingues, L. Valorization of Eucalyptus nitens bark by organosolv pretreatment for the production of advanced biofuels. Ind. Crops Prod. 2019, 132, 327-335. [CrossRef]

33. Neiva, D.M.; Costa, R.A.; Gominho, J.; Ferreira-Dias, S.; Pereira, H. Fractionation and valorization of industrial bark residues by autohydrolysis and enzymatic saccharification. Bioresour. Technol. Reports 2020, 11, 100441. [CrossRef]

34. Ballesteros, L.F.; Michelin, M.; Vicente, A.A.; Teixeira, J.A.; Cerqueira, M.Â. Lignocellulosic Materials and Their Use in Bio- Based Packaging; Springer International Publishing: Cham, Switzerland, 2018.

35. Xu, Y.; Salmi, J.; Kloser, E.; Perrin, F.; Grosse, S.; Denault, J.; Lau, P.C.K. Feasibility of nanocrystalline cellulose production by endoglucanase treatment of natural bast fibers. Ind. Crops Prod. 2013, 51, 381-384. [CrossRef]

36. Qing, Y.; Sabo, R.; Zhu, J.Y.; Agarwal, U.; Cai, Z.; Wu, Y. A comparative study of cellulose nanofibrils disintegrated via multiple processing approaches. Carbohydr. Polym. 2013, 97, 226-234. [CrossRef]

37. Wang, W.; Mozuch, M.D.; Sabo, R.C.; Kersten, P.; Zhu, J.Y.; Jin, Y. Production of cellulose nanofibrils from bleached eucalyptus fibers by hyperthermostable endoglucanase treatment and subsequent microfluidization. Cellulose 2015, 22, 351-361. [CrossRef]

38. Tarrés, Q.; Delgado-Aguilar, M.; Pèlach, M.A.; González, I.; Boufi, S.; Mutjé, P. Remarkable increase of paper strength by combining enzymatic cellulose nanofibers in bulk and TEMPO-oxidized nanofibers as coating. Cellulose 2016, 23, 3939-3950. [CrossRef]

39. Tarrés, Q.; Saguer, E.; Pèlach, M.A.; Alcalà, M.; Delgado-Aguilar, M.; Mutjé, P. The feasibility of incorporating cellulose micro/nanofibers in papermaking processes: The relevance of enzymatic hydrolysis. Cellulose 2016, 23, 1433-1445. [CrossRef]

40. Tarrés, Q.; Boufi, S.; Mutjé, P.; Delgado-Aguilar, M. Enzymatically hydrolyzed and TEMPO-oxidized cellulose nanofibers for the production of nanopapers: Morphological, optical, thermal and mechanical properties. Cellulose 2017, 24, 3943-3954. [CrossRef]

41. Bauli, C.R.; Rocha, D.B.; de Oliveira, S.A.; Rosa, D.S. Cellulose nanostructures from wood waste with low input consumption. J. Clean. Prod. 2019, 211, 408-416. [CrossRef]

42. Beltramino, F.; Blanca Roncero, M.; Vidal, T.; Valls, C. A novel enzymatic approach to nanocrystalline cellulose preparation. Carbohydr. Polym. 2018, 189, 39-47. [CrossRef]

43. Squinca, P.; Bilatto, S.; Badino, A.C.; Farinas, C.S. Nanocellulose production in future biorefineries: An integrated approach using tailor-made enzymes. ACS Sustain. Chem. Eng. 2020, 8, 2277-2286. [CrossRef]

44. Lourenço, A.F.; Gamelas, J.A.F.; Sarmento, P.; Ferreira, P.J.T. Enzymatic nanocellulose in papermaking-The key role as filler flocculant and strengthening agent. Carbohydr. Polym. 2019, 224. [CrossRef]

45. Siqueira, G.A.; Dias, I.K.R.; Arantes, V. Exploring the action of endoglucanases on bleached eucalyptus kraft pulp as potential catalyst for isolation of cellulose nanocrystals. Int. J. Biol. Macromol. 2019, 133, 1249-1259. [CrossRef]

46. Li, L.; Zhuang, J.; Zou, H.; Pang, J.; Yu, S. Partition usage of cellulose by coupling approach of supercritical carbon dioxide and cellulase to reducing sugar and nanocellulose. Carbohydr. Polym. 2020, 229. [CrossRef]

47. Cui, S.; Zhang, S.; Ge, S.; Xiong, L.; Sun, Q. Green preparation and characterization of size-controlled nanocrystalline cellulose via ultrasonic-assisted enzymatic hydrolysis. Ind. Crops Prod. 2016, 83, 346-352. [CrossRef]

48. Tong, X.; Shen, W.; Chen, X.; Jia, M.; Roux, J.C. Preparation and mechanism analysis of morphology-controlled cellulose nanocrystals via compound enzymatic hydrolysis of eucalyptus pulp. J. Appl. Polym. Sci. 2020, 137, 1-11. [CrossRef]

49. Ghafari, R.; Scaffaro, R.; Maio, A.; Gulino, E.F.; Lo Re, G.; Jonoobi, M. Processing-structure-property relationships of electrospun PLA-PEO membranes reinforced with enzymatic cellulose nanofibers. Polym. Test. 2020, 81, 106182. [CrossRef]

50. Sacui, I.A.; Nieuwendaal, R.C.; Burnett, D.J.; Stranick, S.J.; Jorfi, M.; Weder, C.; Foster, E.J.; Olsson, R.T.; Gilman, J.W. Comparison of the properties of cellulose nanocrystals and cellulose nanofibrils isolated from bacteria, tunicate, and wood processed using acid, enzymatic, mechanical, and oxidative methods. ACS Appl. Mater. Interfaces 2014, 6, 6127-6138. [CrossRef] 
51. Rol, F.; Karakashov, B.; Nechyporchuk, O.; Terrien, M.; Meyer, V.; Dufresne, A.; Belgacem, M.N.; Bras, J. Pilot-scale twin screw extrusion and chemical pretreatment as an energy-efficient method for the production of nanofibrillated cellulose at high solid content. ACS Sustain. Chem. Eng. 2017, 5, 6524-6531. [CrossRef]

52. Hu, J.; Tian, D.; Renneckar, S.; Saddler, J.N. Enzyme mediated nanofibrillation of cellulose by the synergistic actions of an endoglucanase, lytic polysaccharide monooxygenase (LPMO) and xylanase. Sci. Rep. 2018, 8, 4-11. [CrossRef]

53. Martelli-Tosi, M.; Torricillas, M.D.S.; Martins, M.A.; de Assis, O.B.G.; Tapia-Blácido, D.R. Using commercial enzymes to produce cellulose nanofibers from soybean straw. J. Nanomater. 2016, 2016, 8106814. [CrossRef]

54. Bondancia, T.J.; Mattoso, L.H.C.; Marconcini, J.M.; Farinas, C.S. A new approach to obtain cellulose nanocrystals and ethanol from eucalyptus cellulose pulp via the biochemical pathway. Biotechnol. Prog. 2017, 33, 1085-1095. [CrossRef] [PubMed]

55. Bondancia, T.J.; Corrêa, L.J.; Cruz, A.J.G.; Badino, A.C.; Mattoso, L.H.C.; Marconcini, J.M.; Farinas, C.S. Enzymatic production of cellulose nanofibers and sugars in a stirred-tank reactor: Determination of impeller speed, power consumption, and rheological behavior. Cellulose 2018, 25, 4499-4511. [CrossRef]

56. Kumari, P.; Pathak, G.; Gupta, R.; Sharma, D.; Meena, A. Cellulose nanofibers from lignocellulosic biomass of lemongrass using enzymatic hydrolysis: Characterization and cytotoxicity assessment. DARU, J. Pharm. Sci. 2019, 27, 683-693. [CrossRef] [PubMed]

57. Tibolla, H.; Pelissari, F.M.; Martins, J.T.; Lanzoni, E.M.; Vicente, A.A.; Menegalli, F.C.; Cunha, R.L. Banana starch nanocomposite with cellulose nanofibers isolated from banana peel by enzymatic treatment: In vitro cytotoxicity assessment. Carbohydr. Polym. 2019, 207, 169-179. [CrossRef] [PubMed]

58. Yassin, M.A.; Gad, A.A.M.; Ghanem, A.F.; Abdel Rehim, M.H. Green synthesis of cellulose nanofibers using immobilized cellulase. Carbohydr. Polym. 2019, 205, 255-260. [CrossRef]

59. Cypriano, D.Z.; da Silva, L.L.; Tasic, L. High value-added products from the orange juice industry waste. Waste Manag. 2018, 79, 71-78. [CrossRef]

60. Martelli-Tosi, M.; Masson, M.M.; Silva, N.C.; Esposto, B.S.; Barros, T.T.; Assis, O.B.G.; Tapia-Blácido, D.R. Soybean straw nanocellulose produced by enzymatic or acid treatment as a reinforcing filler in soy protein isolate films. Carbohydr. Polym. 2018, 198, 61-68. [CrossRef]

61. Hideno, A.; Abe, K.; Yano, H. Preparation using pectinase and characterization of nanofibers from orange peel waste in juice factories. J. Food Sci. 2014, 79, 1218-1224. [CrossRef]

62. de Campos, A.; Correa, A.C.; Cannella, D.; de Teixeira, E.M.; Marconcini, J.M.; Dufresne, A.; Mattoso, L.H.C.; Cassland, P.; Sanadi, A.R. Obtaining nanofibers from curauá and sugarcane bagasse fibers using enzymatic hydrolysis followed by sonication. Cellulose 2013, 20, 1491-1500. [CrossRef]

63. Pääkko, M.; Ankerfors, M.; Kosonen, H.; Nykänen, A.; Ahola, S.; Österberg, M.; Ruokolainen, J.; Laine, J.; Larsson, P.T.; Ikkala, O.; et al. Enzymatic hydrolysis combined with mechanical shearing and high-pressure homogenization for nanoscale cellulose fibrils and strong gels. Biomacromolecules 2007, 8, 1934-1941. [CrossRef]

64. Chen, X.Q.; Pang, G.X.; Shen, W.H.; Tong, X.; Jia, M.Y. Preparation and characterization of the ribbon-like cellulose nanocrystals by the cellulase enzymolysis of cotton pulp fibers. Carbohydr. Polym. 2019, 207, 713-719. [CrossRef]

65. Tang, Y.; Shen, X.; Zhang, J.; Guo, D.; Kong, F.; Zhang, N. Extraction of cellulose nano-crystals from old corrugated container fiber using phosphoric acid and enzymatic hydrolysis followed by sonication. Carbohydr. Polym. 2015, 125, 360-366. [CrossRef]

66. Dai, J.; Chae, M.; Beyene, D.; Danumah, C.; Tosto, F.; Bressler, D.C. Co-production of cellulose nanocrystals and fermentable sugars assisted by endoglucanase treatment of wood pulp. Materials 2018, 11, 1645. [CrossRef]

67. Chen, X.; Deng, X.; Shen, W.; Jiang, L. Controlled enzymolysis preparation of nanocrystalline cellulose from pretreated cotton fibers. BioResources 2012, 7, 4237-4248. [CrossRef]

68. Beltramino, F.; Roncero, M.B.; Torres, A.L.; Vidal, T.; Valls, C. Optimization of sulfuric acid hydrolysis conditions for preparation of nanocrystalline cellulose from enzymatically pretreated fibers. Cellulose 2016, 23, 1777-1789. [CrossRef]

69. Domingues, A.A.; Pereira, F.V.; Sierakowski, M.R.; Rojas, O.J.; Petri, D.F.S. Interfacial properties of cellulose nanoparticles obtained from acid and enzymatic hydrolysis of cellulose. Cellulose 2016, 23, 2421-2437. [CrossRef]

70. Ma, L.; Zhang, Y.; Cao, J.; Yao, J. Preparation of unmodified cellulose nanocrystals from Phyllostachys heterocycla and their biocompatibility evaluation. BioResources 2014, 9, 210-217. [CrossRef] 
71. Satyamurthy, P.; Jain, P.; Balasubramanya, R.H.; Vigneshwaran, N. Preparation and characterization of cellulose nanowhiskers from cotton fibres by controlled microbial hydrolysis. Carbohydr. Polym. 2011, 83, 122-129. [CrossRef]

72. Andlar, M.; Rezić, T.; Marđetko, N.; Kracher, D.; Ludwig, R.; Šantek, B. Lignocellulose degradation: An overview of fungi and fungal enzymes involved in lignocellulose degradation. Eng. Life Sci. 2018, 18, 768-778. [CrossRef]

73. Segato, F.; Damásio, A.R.L.; de Lucas, R.C.; Squina, F.M.; Prade, R.A. Genomics review of holocellulose deconstruction by aspergilli. Microbiol. Mol. Biol. Rev. 2014, 78, 588-613. [CrossRef]

74. Zhao, Y.; Moser, C.; Lindström, M.E.; Henriksson, G.; Li, J. Cellulose nanofibers from softwood, hardwood, and tunicate: Preparation-structure-film performance interrelation. ACS Appl. Mater. Interfaces 2017, 9, 13508-13519. [CrossRef]

75. Meyabadi, T.F.; Dadashian, F. Optimization of enzymatic hydrolysis of waste cotton fibers for nanoparticles production using response surface methodology. Fibers Polym. 2012, 13, 313-321. [CrossRef]

76. Meyabadi, T.F.; Dadashian, F.; Mir Mohamad Sadeghi, G.; Ebrahimi Zanjani Asl, H. Spherical cellulose nanoparticles preparation from waste cotton using a green method. Powder Technol. 2014, 261, 232-240. [CrossRef]

77. Song, Q.; Winter, W.T.; Bujanovic, B.M.; Amidon, T.E. Nanofibrillated cellulose (NFC): A high-value co-product that improves the economics of cellulosic ethanol production. Energies 2014, 7, 607-618. [CrossRef]

78. Hu, J.; Arantes, V.; Saddler, J.N. The enhancement of enzymatic hydrolysis of lignocellulosic substrates by the addition of accessory enzymes such as xylanase: Is it an additive or synergistic effect? Biotechnol. Biofuels 2011, 4. [CrossRef]

79. Laivins, G.V.; Scallan, A.M. The mechanism of hornification of wood pulps. In Products of Papermaking, Trans. of the Xth Fund. Res. Symp. Oxford; Baker, C.F., Ed.; FRC: Manchester, UK, 1993; pp. 1235-1260.

80. Winter, H.T.; Cerclier, C.; Delorme, N.; Bizot, H.; Quemener, B.; Cathala, B. Improved colloidal stability of bacterial cellulose nanocrystal suspensions for the elaboration of spin-coated cellulose-based model surfaces. Biomacromolecules 2010, 11, 3144-3151. [CrossRef]

81. 81 Tibolla, H.; Pelissari, F.M.; Menegalli, F.C. Cellulose nanofibers produced from banana peel by chemical and enzymatic treatment. LWT-Food Sci. Technol. 2014, 59, 1311-1318. [CrossRef]

82. Hassan, M.L.; Bras, J.; Hassan, E.A.; Silard, C.; Mauret, E. Enzyme-assisted isolation of microfibrillated cellulose from date palm fruit stalks. Ind. Crops Prod. 2014, 55, 102-108. [CrossRef]

83. Pengilly, C.; García-Aparicio, M.P.; Diedericks, D.; Brienzo, M.; Görgens, J.F. Enzymatic hydrolysis of steam-pretreated sweet sorghum bagasse by combinations of cellulase and endo-xylanase. Fuel 2015, 154, 352-360. [CrossRef]

84. de Figueiredo, V.R.G.; Yamashita, F.; Vanzela, A.L.L.; Ida, E.I.; Kurozawa, L.E. Action of multi-enzyme complex on protein extraction to obtain a protein concentrate from okara. J. Food Sci. Technol. 2018, 55, 1508-1517. [CrossRef]

85. Filson, P.B.; Dawson-Andoh, B.E.; Schwegler-Berry, D. Enzymatic-mediated production of cellulose nanocrystals from recycled pulp. Green Chem. 2009, 11, 1808-1814. [CrossRef]

86. Chen, X.Q.; Deng, X.Y.; Shen, W.H.; Jia, M.Y. Preparation and characterization of the spherical nanosized cellulose by the enzymatic hydrolysis of pulp fibers. Carbohydr. Polym. 2018, 181, 879-884. [CrossRef]

87. Villares, A.; Moreau, C.; Bennati-Granier, C.; Garajova, S.; Foucat, L.; Falourd, X.; Saake, B.; Berrin, J.G.; Cathala, B. Lytic polysaccharide monooxygenases disrupt the cellulose fibers structure. Sci. Rep. 2017, 7, 1-9. [CrossRef]

88. Levasseur, A.; Drula, E.; Lombard, V.; Coutinho, P.M.; Henrissat, B. Expansion of the enzymatic repertoire of the CAZy database to integrate auxiliary redox enzymes. Biotechnol. Biofuels 2013, 6, 1-14. [CrossRef]

89. Couturier, M.; Navarro, D.; Chevret, D.; Henrissat, B.; Piumi, F.; Ruiz-Dueñas, F.J.; Martinez, A.T.; Grigoriev, I.V.; Riley, R.; Lipzen, A.; et al. Enhanced degradation of softwood versus hardwood by the white-rot fungus Pycnoporus coccineus. Biotechnol. Biofuels 2015, 8, 1-16. [CrossRef]

90. Valls, C.; Javier Pastor, F.I.; Blanca Roncero, M.; Vidal, T.; Diaz, P.; Martínez, J.; Valenzuela, S.V. Assessing the enzymatic effects of cellulases and LPMO in improving mechanical fibrillation of cotton linters. Biotechnol. Biofuels 2019, 12, 1-14. [CrossRef] 
91. Seo, D.J.; Fujita, H.; Sakoda, A. Effects of a non-ionic surfactant, Tween 20, on adsorption/desorption of saccharification enzymes onto/from lignocelluloses and saccharification rate. Adsorption 2011, 17, 813-822. [CrossRef]

92. Saini, J.K.; Patel, A.K.; Adsul, M.; Singhania, R.R. Cellulase adsorption on lignin: A roadblock for economic hydrolysis of biomass. Renew. Energy 2016, 98, 29-42. [CrossRef]

93. Wang, W.; Zhu, Y.; Du, J.; Yang, Y.; Jin, Y. Influence of lignin addition on the enzymatic digestibility of pretreated lignocellulosic biomasses. Bioresour. Technol. 2015, 181, 7-12. [CrossRef] [PubMed]

94. Kumar, L.; Arantes, V.; Chandra, R.; Saddler, J. The lignin present in steam pretreated softwood binds enzymes and limits cellulose accessibility. Bioresour. Technol. 2012, 103, 201-208. [CrossRef]

95. Tu, M.; Chandra, R.P.; Saddler, J.N. Evaluating the distribution of cellulases and the recycling of free cellulases during the hydrolysis of lignocellulosic substrates. Biotechnol. Prog. 2007, 23, 398-406. [CrossRef]

96. Gomes, D.; Gama, M.; Domingues, L. Determinants on an efficient cellulase recycling process for the production of bioethanol from recycled paper sludge under high solid loadings. Biotechnol. Biofuels 2018, 11, 1-12. [CrossRef]

97. Gomes, D.; Rodrigues, A.C.; Domingues, L.; Gama, M. Cellulase recycling in biorefineries-Is it possible? Appl. Microbiol. Biotechnol. 2015, 99, 4131-4143. [CrossRef]

98. McLean, B.W.; Boraston, A.B.; Brouwer, D.; Sanaie, N.; Fyfe, C.A.; Warren, R.A.J.; Kilburn, D.G.; Haynes, C.A. Carbohydrate-binding modules recognize fine substructures of cellulose. J. Biol. Chem. 2002, 277, 50245-50254. [CrossRef]

99. Jørgensen, H.; Kristensen, J.B.; Felby, C. Enzymatic conversion of lignocellulose into fermentable sugars: Challenges and opportunities. Biofuels, Bioprod. Biorefining 2007, 1, 119-134. [CrossRef]

100. Rodrigues, A.C.; Leitão, A.F.; Moreira, S.; Felby, C.; Gama, M. Recycling of cellulases in lignocellulosic hydrolysates using alkaline elution. Bioresour. Technol. 2012, 110, 526-533. [CrossRef] [PubMed]

101. Adnan, S.; Azhar, A.H.; Jasmani, L.; Samsudin, M.F. Properties of paper incorporated with nanocellulose extracted using microbial hydrolysis assisted shear process. IOP Conf. Ser. Mater. Sci. Eng. 2018, 368. [CrossRef]

102. Chávez-Guerrero, L.; Silva-Mendoza, J.; Sepúlveda-Guzmán, S.; Medina-Aguirre, N.A.; Vazquez-Rodriguez, S.; Cantú-Cárdenas, M.E.; García-Gómez, N.A. Enzymatic hydrolysis of cellulose nanoplatelets as a source of sugars with the concomitant production of cellulose nanofibrils. Carbohydr. Polym. 2019, 210, 85-91. [CrossRef]

103. Teixeira, R.S.S.; Da Silva, A.S.A.; Jang, J.H.; Kim, H.W.; Ishikawa, K.; Endo, T.; Lee, S.H.; Bon, E.P.S. Combining biomass wet disk milling and endoglucanase/ $\beta$-glucosidase hydrolysis for the production of cellulose nanocrystals. Carbohydr. Polym. 2015, 128, 75-81. [CrossRef]

104. Satyamurthy, P.; Vigneshwaran, N. A novel process for synthesis of spherical nanocellulose by controlled hydrolysis of microcrystalline cellulose using anaerobic microbial consortium. Enzyme Microb. Technol. 2013, 52, 20-25. [CrossRef]

105. Tu, M.; Zhang, X.; Paice, M.; MacFarlane, P.; Saddler, J.N. The potential of enzyme recycling during the hydrolysis of a mixed softwood feedstock. Bioresour. Technol. 2009, 100, 6407-6415. [CrossRef]

106. Brunecky, R.; Alahuhta, M.; Xu, Q.; Donohoe, B.S.; Crowley, M.F.; Kataeva, I.A.; Yang, S.J.; Resch, M.G.; Adams, M.W.W.; Lunin, V.V.; et al. Revealing nature's cellulase diversity: The digestion mechanism of Caldicellulosiruptor bescii CelA. Science 2013, 342, 1513-1516. [CrossRef] [PubMed]

107. Tsukamoto, J.; Durán, N.; Tasic, L. Nanocellulose and bioethanol production from orange waste using isolated microorganisms. J. Braz. Chem. Soc. 2013, 24, 1537-1543. [CrossRef]

108. Guirimand, G.; Inokuma, K.; Bamba, T.; Matsuda, M.; Morita, K.; Sasaki, K.; Ogino, C.; Berrin, J.G.; Hasunuma, T.; Kondo, A. Cell-surface display technology and metabolic engineering of: Saccharomyces cerevisiae for enhancing xylitol production from woody biomass. Green Chem. 2019, 21, 1795-1808. [CrossRef]

109. Lee, H.V.; Hamid, S.B.A.; Zain, S.K. Conversion of lignocellulosic biomass to nanocellulose: Structure and chemical process. Sci. World J. 2014, 2014, 631013. [CrossRef]

110. Salimi, S.; Sotudeh-Gharebagh, R.; Zarghami, R.; Chan, S.Y.; Yuen, K.H. Production of nanocellulose and its applications in drug delivery: A critical review. ACS Sustain. Chem. Eng. 2019, 7, 15800-15827. [CrossRef]

111. Mokhena, T.C.; John, M.J. Cellulose Nanomaterials: New Generation Materials for Solving Global Issues; Springer: Amsterdam, The Netherlands, 2020.

112. Piccinno, F.; Hischier, R.; Seeger, S.; Som, C. Life cycle assessment of a new technology to extract, functionalize and orient cellulose nanofibers from food waste. ACS Sustain. Chem. Eng. 2015, 3, 1047-1055. [CrossRef] 
113. de Figueirêdo, M.C.B.; de Freitas Rosa, M.; Lie Ugaya, C.M.; de Souza Filho, M.D.S.M.; Da Silva Braid, A.C.C.; de Melo, L.F.L. Life cycle assessment of cellulose nanowhiskers. J. Clean. Prod. 2012, 35, 130-139. [CrossRef]

114. Li, Q.; McGinnis, S.; Sydnor, C.; Wong, A.; Renneckar, S. Nanocellulose life cycle assessment. ACS Sustain. Chem. Eng. 2013, 1, 919-928. [CrossRef]

115. Kargarzadeh, H.; Mariano, M.; Gopakumar, D.; Ahmad, I.; Thomas, S.; Dufresne, A.; Huang, J.; Lin, N. Advances in Cellulose Nanomaterials; Springer: Amsterdam, The Netherlands, 2018.

116. Xu, X.; Wang, H.; Jiang, L.; Wang, X.; Payne, S.A.; Zhu, J.Y.; Li, R. Comparison between cellulose nanocrystal and cellulose nanofibril reinforced poly(ethylene oxide) nanofibers and their novel shish-kebab-like crystalline structures. Macromolecules 2014, 47, 3409-3416. [CrossRef]

117. Himmel, M.E.; Ding, S.Y.; Johnson, D.K.; Adney, W.S.; Nimlos, M.R.; Brady, J.W.; Foust, T.D. Biomass recalcitrance: Engineering plants and enzymes for biofuels production. Science 2007, 315, 804-807. [CrossRef]

118. Abdul Khalil, H.P.S.; Davoudpour, Y.; Islam, M.N.; Mustapha, A.; Sudesh, K.; Dungani, R.; Jawaid, M. Production and modification of nanofibrillated cellulose using various mechanical processes: A review. Carbohydr. Polym. 2014, 99, 649-665. [CrossRef] [PubMed]

119. Xie, H.; Du, H.; Yang, X.; Si, C. Recent strategies in preparation of cellulose nanocrystals and cellulose nanofibrils derived from raw cellulose materials. Int. J. Polym. Sci. 2018, 2018, 7923068. [CrossRef]

120. Henriksson, M.; Henriksson, G.; Berglund, L.A.; Lindström, T. An environmentally friendly method for enzyme-assisted preparation of microfibrillated cellulose (MFC) nanofibers. Eur. Polym. J. 2007, 43, 3434-3441. [CrossRef]

121. George, J.; Sabapathi, S.N. Cellulose nanocrystals: Synthesis, functional properties, and applications. Nanotechnol. Sci. Appl. 2015, 8, 45-54. [CrossRef] [PubMed]

122. Beck-Candanedo, S.; Roman, M.; Gray, D.G. Effect of reaction conditions on the properties and behavior of wood cellulose nanocrystal suspensions. Biomacromolecules 2005, 6, 1048-1054. [CrossRef]

123. Gomes, D.G.; Serna-Loaiza, S.; Cardona, C.A.; Gama, M.; Domingues, L. Insights into the economic viability of cellulases recycling on bioethanol production from recycled paper sludge. Bioresour. Technol. 2018, 267, 347-355. [CrossRef]

124. Gomes, D.; Domingues, L.; Gama, M. Valorizing recycled paper sludge by a bioethanol production process with cellulase recycling. Bioresour. Technol. 2016, 216, 637-644. [CrossRef]

125. Rojas, J.; Bedoya, M.; Ciro, Y. Current Trends in the Production of Cellulose Nanoparticles and Nanocomposites for Biomedical Applications; Cellulose-Fundamental Aspects and Current Trends; Poletto, M., Ornaghi, H.L., Jr., Eds.; Intech Open: London, UK, 2015; pp. 193-228.

126. Rajinipriya, M.; Nagalakshmaiah, M.; Robert, M.; Elkoun, S. Importance of agricultural and industrial waste in the field of nanocellulose and recent industrial developments of wood based nanocellulose: A review. ACS Sustain. Chem. Eng. 2018, 6, 2807-2828. [CrossRef]

127. Hoeng, F.; Denneulin, A.; Bras, J. Use of nanocellulose in printed electronics: A review. Nanoscale 2016, 8, 13131-13154. [CrossRef]

128. Lu, P.; Hsieh, Y. Lo Cellulose isolation and core-shell nanostructures of cellulose nanocrystals from chardonnay grape skins. Carbohydr. Polym. 2012, 87, 2546-2553. [CrossRef]

129. Xu, J.T.; Chen, X.Q. Preparation and characterization of spherical cellulose nanocrystals with high purity by the composite enzymolysis of pulp fibers. Bioresour. Technol. 2019, 291, 121842. [CrossRef]

130. Anderson, S.R.; Esposito, D.; Gillette, W.; Zhu, J.Y.; Baxa, U.; McNeil, S.E. Enzymatic preparation of nanocrystalline and microcrystalline cellulose. Tappi J. 2014, 13, 35-42. [CrossRef]

131. Dufresne, A. Nanocellulose: From Nature to High Performance Tailored Materials; CPI books GmbH: Leck, Germany, 2012.

132. Wang, Q.Q.; Zhu, J.Y.; Reiner, R.S.; Verrill, S.P.; Baxa, U.; McNeil, S.E. Approaching zero cellulose loss in cellulose nanocrystal (CNC) production: Recovery and characterization of cellulosic solid residues (CSR) and CNC. Cellulose 2012, 19, 2033-2047. [CrossRef]

133. Sun, B.; Hou, Q.; Liu, Z.; Ni, Y. Sodium periodate oxidation of cellulose nanocrystal and its application as a paper wet strength additive. Cellulose 2015, 22, 1135-1146. [CrossRef]

134. Tonoli, G.H.D.; Teixeira, E.M.; Corrêa, A.C.; Marconcini, J.M.; Caixeta, L.A.; Pereira-Da-Silva, M.A.; Mattoso, L.H.C. Cellulose micro/nanofibres from Eucalyptus kraft pulp: Preparation and properties. Carbohydr. Polym. 2012, 89, 80-88. [CrossRef] 
135. Xu, X.; Liu, F.; Jiang, L.; Zhu, J.Y.; Haagenson, D.; Wiesenborn, D.P. Cellulose nanocrystals vs. Cellulose nanofibrils: A comparative study on their microstructures and effects as polymer reinforcing agents. ACS Appl. Mater. Interfaces 2013, 5, 2999-3009. [CrossRef]

136. Claro, P.I.C.; Corrêa, A.C.; de Campos, A.; Rodrigues, V.B.; Luchesi, B.R.; Silva, L.E.; Mattoso, L.H.C.; Marconcini, J.M. Curaua and eucalyptus nanofibers films by continuous casting: Mechanical and thermal properties. Carbohydr. Polym. 2018, 181, 1093-1101. [CrossRef]

137. Chen, Y.; He, Y.; Fan, D.; Han, Y.; Li, G.; Wang, S. An efficient method for cellulose nanofibrils length shearing via environmentally friendly mixed cellulase pretreatment. J. Nanomater. 2017, 2017, 1591504. [CrossRef]

138. Moon, R.J.; Martini, A.; Nairn, J.; Simonsen, J.; Youngblood, J. Cellulose Nanomaterials Review: Structure, Properties and Nanocomposites; Royal Society of Chemistry: London, UK, 2011.

139. Zhao, J.; He, X.; Wang, Y.; Zhang, W.; Zhang, X.; Zhang, X.; Deng, Y.; Lu, C. Reinforcement of all-cellulose nanocomposite films using native cellulose nanofibrils. Carbohydr. Polym. 2014, 104, 143-150. [CrossRef]

140. Johansson, C.; Bras, J.; Mondragon, I.; Nechita, P.; Plackett, D.; Šimon, P.; Svetec, D.G.; Virtanen, S.; Baschetti, M.G.; Breen, C.; et al. Renewable fibers and bio-based materials for packaging applications-A review of recent developments. BioResources 2012, 7, 2506-2552. [CrossRef]

141. Tao, P.; Wu, Z.; Xing, C.; Zhang, Q.; Wei, Z.; Nie, S. Effect of enzymatic treatment on the thermal stability of cellulose nanofibrils. Cellulose 2019, 26, 7717-7725. [CrossRef]

142. Minelli, M.; Baschetti, M.G.; Doghieri, F.; Ankerfors, M.; Lindström, T.; Siró, I.; Plackett, D. Investigation of mass transport properties of microfibrillated cellulose (MFC) films. J. Memb. Sci. 2010, 358, 67-75. [CrossRef]

143. Belbekhouche, S.; Bras, J.; Siqueira, G.; Chappey, C.; Lebrun, L.; Khelifi, B.; Marais, S.; Dufresne, A. Water sorption behavior and gas barrier properties of cellulose whiskers and microfibrils films. Carbohydr. Polym. 2011, 83, 1740-1748. [CrossRef]

144. Spence, K.L.; Venditti, R.A.; Rojas, O.J.; Habibi, Y.; Pawlak, J.J. The effect of chemical composition on microfibrillar cellulose films from wood pulps: Water interactions and physical properties for packaging applications. Cellulose 2010, 17, 835-848. [CrossRef]

145. Syverud, K.; Stenius, P. Strength and barrier properties of MFC films. Cellulose 2008, 16, 75. [CrossRef]

146. Parry, R.T. Principles and Applications of Modified Atmosphere Packaging of Foods; Elsevier: Amsterdam, The Netherlands, 1993.

147. Fukuzumi, H.; Saito, T.; Iwata, T.; Kumamoto, Y.; Isogai, A. Transparent and high gas barrier films of cellulose nanofibers prepared by TEMPO-mediated oxidation. Biomacromolecules 2009, 10, 162-165. [CrossRef]

148. Rodionova, G.; Saito, T.; Lenes, M.; Eriksen, Ø.; Gregersen, Ø.; Fukuzumi, H.; Isogai, A. Mechanical and oxygen barrier properties of films prepared from fibrillated dispersions of TEMPO-oxidized Norway spruce and Eucalyptus pulps. Cellulose 2012, 19, 705-711. [CrossRef]

149. Aulin, C.; Gällstedt, M.; Lindström, T. Oxygen and oil barrier properties of microfibrillated cellulose films and coatings. Cellulose 2010, 17, 559-574. [CrossRef]

150. Snyder, J.F.; Steele, J.; Dong, H.; Orlicki, J.A.; Reiner, R.S.; Rudie, A.W. Optical properties of nanocellulose dispersions in water, dimethylformamide and poly (methyl methacrylate). Army Res. Lab. 2013.

151. Hu, L.; Zheng, G.; Yao, J.; Liu, N.; Weil, B.; Eskilsson, M.; Karabulut, E.; Ruan, Z.; Fan, S.; Bloking, J.T.; et al. Transparent and conductive paper from nanocellulose fibers. Energy Environ. Sci. 2013, 6, 513-518. [CrossRef]

152. Beck, S.; Bouchard, J.; Berry, R. Controlling the reflection wavelength of iridescent solid films of nanocrystalline cellulose. Biomacromolecules 2011, 12, 167-172. [CrossRef] [PubMed]

153. Ioelovich, M.; Leykin, A. Structural characteristics and rheological properties of microcrystalline cellulose. Cellul. Chem. Technol. 2006, 40, 699-703.

154. Tatsumi, D.; Ishioka, S.; Matsumoto, T. Effect of fiber concentration and axial ratio on the rheological properties of cellulose fiber suspensions. Nihon Reoroji Gakkaishi 2002, 30, 27-32. [CrossRef]

155. MarketsandMarkets Nanocellulose Market. Available online: https://www.marketsandmarkets.com/MarketReports/nano-cellulose-market-56392090.html2020. (accessed on 22 June 2020).

156. Mu, R.; Hong, X.; Ni, Y.; Li, Y.; Pang, J.; Wang, Q.; Xiao, J.; Zheng, Y. Recent trends and applications of cellulose nanocrystals in food industry. Trends Food Sci. Technol. 2019, 93, 136-144. [CrossRef]

157. Bharimalla, A.K.; Deshmukh, S.P.; Vigneshwaran, N.; Patil, P.G.; Prasad, V. Nanocellulose-polymer composites for applications in food packaging: Current status, future prospects and challenges. Polym.-Plast. Technol. Eng. 2017, 56, 805-823. [CrossRef] 
158. Gómez, H.C.; Serpa, A.; Velásquez-Cock, J.; Gañán, P.; Castro, C.; Vélez, L.; Zuluaga, R. Vegetable nanocellulose in food science: A review. Food Hydrocoll. 2016, 57, 178-186. [CrossRef]

159. Yang, Q.; Saito, T.; Berglund, L.A.; Isogai, A. Cellulose nanofibrils improve the properties of all-cellulose composites by the nano-reinforcement mechanism and nanofibril-induced crystallization. Nanoscale 2015, 7, 17957-17963. [CrossRef]

160. Nascimento, D.M.; Nunes, Y.L.; Figueirêdo, M.C.B.; de Azeredo, H.M.C.; Aouada, F.A.; Feitosa, J.P.A.; Rosa, M.F.; Dufresne, A. Nanocellulose nanocomposite hydrogels: Technological and environmental issues. Green Chem. 2018, 20, 2428-2448. [CrossRef]

161. Kangas, H.; Pere, J. High-consistency enzymatic fibrillation (HefCel)-A cost-efficient way to produce cellulose nanofibrils (CNF). Adv. Mater.-TechConnect Briefs 2016, 1, 181-183.

162. Du, X.; Zhang, Z.; Liu, W.; Deng, Y. Nanocellulose-based conductive materials and their emerging applications in energy devices-A review. Nano Energy 2017, 35, 299-320. [CrossRef]

163. Vilela, C.; Silvestre, A.J.D.; Figueiredo, F.M.L.; Freire, C.S.R. Nanocellulose-based materials as components of polymer electrolyte fuel cells. J. Mater. Chem. A 2019, 7, 20045-20074. [CrossRef]

164. Patel, D.K.; Dutta, S.D.; Lim, K.T. Nanocellulose-based polymer hybrids and their emerging applications in biomedical engineering and water purification. RSC Adv. 2019, 9, 19143-19162. [CrossRef]

165. Mahfoudhi, N.; Boufi, S. Nanocellulose as a novel nanostructured adsorbent for environmental remediation: A review. Cellulose 2017, 24, 1171-1197. [CrossRef]

166. Du, H.; Liu, W.; Zhang, M.; Si, C.; Zhang, X.; Li, B. Cellulose nanocrystals and cellulose nanofibrils based hydrogels for biomedical applications. Carbohydr. Polym. 2019, 209, 130-144. [CrossRef]

167. Tayeb, A.H.; Amini, E.; Ghasemi, S.; Tajvidi, M. Cellulose nanomaterials-binding properties and applications: A review. Molecules 2018, 23, 2684. [CrossRef]

168. Bacakova, L.; Pajorova, J.; Bacakova, M.; Skogberg, A.; Kallio, P.; Kolarova, K.; Svorcik, V. Versatile application of nanocellulose: From industry to skin tissue engineering and wound healing. Nanomaterials 2019, 9, 164. [CrossRef]

169. Domingues, R.M.A.; Gomes, M.E.; Reis, R.L. The potential of cellulose nanocrystals in tissue engineering strategies. Biomacromolecules 2014, 15, 2327-2346. [CrossRef]

170. Xu, W.; Wang, X.; Sandler, N.; Willför, S.; Xu, C. Three-dimensional printing of wood-derived biopolymers: A review focused on biomedical applications. ACS Sustain. Chem. Eng. 2018, 6, 5663-5680. [CrossRef]

171. Shao, Y.; Chaussy, D.; Grosseau, P.; Beneventi, D. Use of microfibrillated cellulose/lignosulfonate blends as carbon precursors: Impact of hydrogel rheology on 3D printing. Ind. Eng. Chem. Res. 2015, 54, 10575-10582. [CrossRef]

172. Nguyen, D.; Hgg, D.A.; Forsman, A.; Ekholm, J.; Nimkingratana, P.; Brantsing, C.; Kalogeropoulos, T.; Zaunz, S.; Concaro, S.; Brittberg, M.; et al. Cartilage tissue engineering by the 3D bioprinting of iPS cells in a nanocellulose/alginate bioink. Sci. Rep. 2017, 7, 2687. [CrossRef] [PubMed]

173. Markstedt, K.; Mantas, A.; Tournier, I.; Martínez Ávila, H.; Hägg, D.; Gatenholm, P. 3D bioprinting human chondrocytes with nanocellulose-alginate bioink for cartilage tissue engineering applications. Biomacromolecules 2015, 16, 1489-1496. [CrossRef] [PubMed]

174. Doench, I.; Torres-Ramos, M.E.W.; Montembault, A.; de Oliveira, P.N.; Halimi, C.; Viguier, E.; Heux, L.; Siadous, R.; Thiré, R.M.S.M.; Osorio-Madrazo, A. Injectable and gellable chitosan formulations filled with cellulose nanofibers for intervertebral disc tissue engineering. Polymers 2018, 10, 1202. [CrossRef] [PubMed]

175. Liu, A.; Walther, A.; Ikkala, O.; Belova, L.; Berglund, L.A. Clay nanopaper with tough cellulose nanofiber matrix for fire retardancy and gas barrier functions. Biomacromolecules 2011, 12, 633-641. [CrossRef]

176. Carosio, F.; Cuttica, F.; Medina, L.; Berglund, L.A. Clay nanopaper as multifunctional brick and mortar fire protection coating-Wood case study. Mater. Des. 2016, 93, 357-363. [CrossRef]

177. Fonseca, L.M.; Parreiras, L.S.; Murakami, M.T. Rational engineering of the Trichoderma reesei RUT-C30 strain into an industrially relevant platform for cellulase production. Biotechnol. Biofuels 2020, 13, 1-15. [CrossRef]

(C) 2020 by the authors. Licensee MDPI, Basel, Switzerland. This article is an open access article distributed under the terms and conditions of the Creative Commons Attribution (CC BY) license (http://creativecommons.org/licenses/by/4.0/). 